\title{
Seismic Performance of Midstory Isolated Structures under Near-Field Pulse-Like Ground Motion and Limiting Deformation of Isolation Layers
}

\author{
Guiyun $\operatorname{Yan}^{1}$ and Fuquan Chen ${ }^{2}$ \\ ${ }^{1}$ Department of Civil Engineering, Fujian University of Technology, Fuzhou 350118, China \\ ${ }^{2}$ Department of Civil Engineering, Fuzhou University, Fuzhou 350116, China \\ Correspondence should be addressed to Guiyun Yan; yanguiyun@sina.com
}

Received 5 December 2014; Accepted 19 March 2015

Academic Editor: Tai Thai

Copyright (C) 2015 G. Yan and F. Chen. This is an open access article distributed under the Creative Commons Attribution License, which permits unrestricted use, distribution, and reproduction in any medium, provided the original work is properly cited.

Excessive deformation of the isolation layer in midstory isolated structures may occur under strong near-field pulse-like ground motion, which would result in the overturning collapse of the superstructure. The objective of the present research is to limit excessive deformation of the isolation layer and to reduce nonlinear response of midstory isolated structures. To this end, a protective system is presented to limit deformation of the isolation layer by soft pounding. Based on the Kelvin pounding model, a mechanical model is put forward for this protective system. In addition, a new method has been proposed that synthesizes artificial near-field pulse-like ground motion by combining the real near-field nonpulse ground motion with simple equivalent pulses. Also, the impact of artificial near-field pulse-like ground motion on the nonlinear response of midstory isolated structures and the deformation of the isolation layer has been investigated. The effectiveness of the midstory isolation with the protective system has been validated. The results show that the maximum deformation of the isolation layer significantly exceeds the allowable deformation of lead-rubber bearings when subjected to near-field pulse-like ground motion, and it causes the lead-rubber bearings destruction. The proposed protective system is effective in restricting the excessive deformation of the isolation layer and reducing nonlinear responses of the isolated structure, preventing collapse of the superstructure.

\section{Introduction}

Midstory isolation design, in which the isolation system is typically installed on the middle story of a building but not at the base of the building, is a prospective technology aimed at protecting the building from strong earthquake ground motion [1-3]. It has recently gained popularity because it can satisfy both aesthetic architectural concerns and functionality concerns. More importantly, it can enhance the construction feasibility in highly populated areas where installing an isolation system beneath the base of a building can be extremely difficult if the building separation and property line are particular concerns. The effectiveness has been proven regarding midstory isolation's role in reducing seismic demand on the superstructure above the isolation system subject to far-field ground motion [4-7].
Near-field ground motion is characterized by longperiod, short-duration, and high-energy velocity pulses. In the past decade, a great deal of research on the performance of base-isolated structures subjected to near-field ground motion has been carried out [8-10]. However, seismic responses of midstory isolated structures under near-field pulse-like ground motion are seldom explored and may be different from those under nonpulse ground motion. Tan et al. [11] worked on seismic control of interstory isolated eccentric structures subjected to near-field ground motion. Li et al. [12] investigated dynamic responses of an irregular eight-story building with a midstory isolation system under near-field earthquake conditions. Ma et al. [13] analyzed the seismic performance of first-floor column top isolation structures subjected to near-field ground motion considering $P-\Delta$ effects; they found that a velocity pulse of near-field 
ground motion caused larger story drifts at the isolation layer of the structures. Du and Wang [14] conducted research on collapse simulations of midstory isolation structures subjected to multidimensional earthquakes, indicating that greater deformation of the isolation layer occurred and destroyed the isolation bearings. The above studies focused on the linear responses of midstory isolated structures. However, the substructure of midstory isolation is similar to an aseismic system and may undergo plastic deformation under strong near-field pulse-like ground motion, resulting in nonlinear performance that may be significantly different from a linear approximation. Furthermore, excessive deformation of the isolation layer may occur as a result of long-period velocity pulses. This would destroy the isolation bearings and even lead to the overturning collapse of the superstructure. Thus, it is critical to limit the maximum deformation of the isolation layer within the allowable deformation of the isolation bearings. The current studies have seldom taken the above facts into account.

This paper examines the effectiveness of the proposed protective system designed to limit the excessive deformation of the isolation layer and reduce nonlinear responses of the midstory isolated structure. The impact of near-field pulse-like ground motion on seismic behavior of the isolated structure has also been investigated. To this end, combining the real near-field nonpulse ground motion with simple equivalent pulses can simulate artificial near-field pulse-like ground motion. The effects of characteristic parameters of near-field ground motion, such as pulse type, pulse contributing factor, and pulse period, on the nonlinear responses of the midisolated structure and maximum deformation of isolation layer are discussed afterward. Moreover, a protective system has been developed to limit deformation of the isolation layer through soft pounding. Based on the Kelvin pounding model, a mechanical model of the protective system has been established, and the equations of motion for the midstory isolated structure with the protective system are further formulated. Next, comparative analyses are carried out for the dynamic responses of the isolated structure with and without the protective system. Finally, the influence of the protective system's parameters, including reserve space $d_{0}$, limiting stiffness $k_{s}$, reserve pounding space $d_{u}$, and pounding stiffness $k_{p}$ on seismic performance of the isolated structure, has been explored. The outcomes of this work will provide a practical basis for the application of midstory isolated structures in near-field regions.

\section{Protective System of Isolation Layer}

As shown in Figure 1, this protective system of the isolation layer consists of a linear spiral spring, high-damping rubber, a rigid panel, a stiffener, and an affiliation. In the figure, $d_{0}$ is the reserve space of the linear spiral spring to limit the deformation of the isolation layer, $d_{u}$ is the reserve space of the high-damping rubber to soft pounding with a superfloor above the isolation system and $t_{p}$ is the thickness of the highdamping rubber.

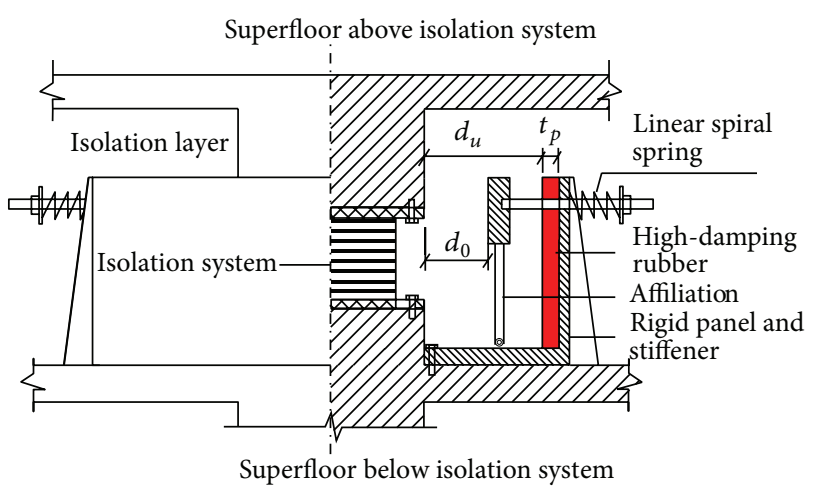

Figure 1: Protective system for limiting deformation of isolation layer.

The mechanism of the protective system for limiting the deformation of the isolation layer is described as follows: the protective system does not influence the isolation effect if the maximum deformation of the isolation layer is less than $d_{0}$, when the midstory isolated structure is subjected to frequent ground motion. While the maximum deformation of isolation layer exceeds $d_{0}$ under strong ground motion, the linear spiral spring will have already begun its function and will produce a restoring force, increasing as its displacement increases, which acts on the superfloor above the isolation system. This restoring force, along with isolation system, decreases the isolation layer's deformation. While the maximum deformation of the isolation layer surpasses $d_{u}$ under the condition that the strong ground motion is beyond preassumption, the superfloor above the isolation system will collide with the high-damping rubber, which plays the role of a bumper to avoid rigid pounding. The high-damping rubber bumper also restricts the maximum deformation of the isolation layer, preventing the destruction of the isolation system.

\section{Mechanical Model of Protective System for Limiting Deformation of Isolation Layer}

3.1. Kelvin Model. In studies of earthquake-induced pounding between adjacent structures, for example, buildings or bridge deck segments, the collisions are usually simulated using Kelvin impact elements of the spring-dashpot type [15]. The presence of the dashpot makes the collisions inelastic, allowing the value of the dashpot constant to reflect the energy losses during the collisions. The impact force $F_{c}$ in the Kelvin model can be expressed as

$$
F_{c}=\left[k_{p}\left(u_{1}-u_{2}-g_{p}\right)+c_{p}\left(\dot{u}_{1}-\dot{u}_{2}\right)\right] \cdot H\left(u_{1}-u_{2}-g_{p}\right) \text {, }
$$

where $u_{1}$ and $u_{2}$ are the displacements of the adjacent bodies at the contact point, $g_{p}$ is the initial gap between the two bodies, $H(\cdot)$ is Heaviside step function, and $k_{p}$ and $c_{p}$ are the 


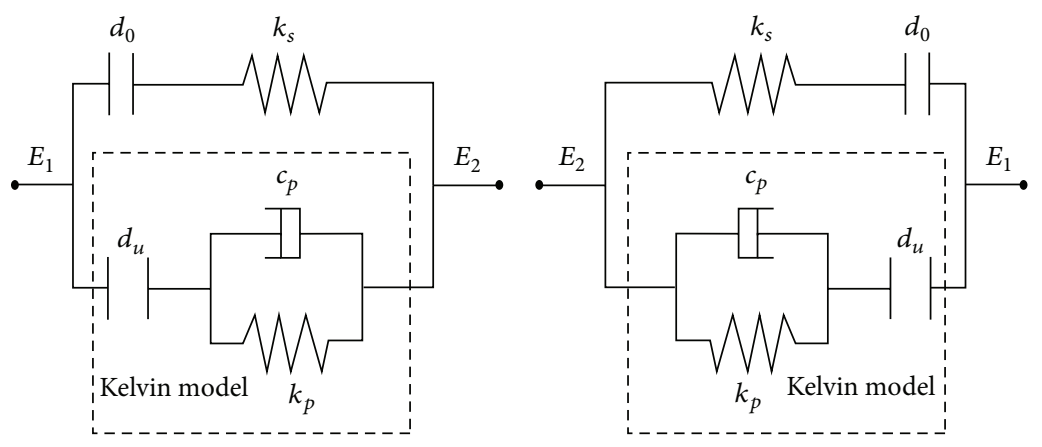

(a)

(b)

FIGURE 2: Mechanical model of protective system. (a) Right-sided limiting deformation; (b) left-sided limiting deformation.

impact stiffness and damping coefficient of the Kelvin impact element, respectively. $c_{p}$ can be calculated as

$$
c_{p}=2 \xi \sqrt{k_{p} \frac{m_{1} m_{2}}{m_{1}+m_{2}}},
$$

where $m_{1}$ and $m_{2}$ are the masses of bodies and $\xi$ is a parameter related to coefficient of restitution $e$ and can be calculated as

$$
\xi=-\frac{\ln e}{\sqrt{\pi^{2}+(\ln e)^{2}}} .
$$

3.2. Mechanical Model for the Protective System. An effective way of reducing the superstructure's responses and providing additional damping to the system is to fill the gap with a viscoelastic material, for example, high-damping rubber, as shown in Figure 1. The behavior of such a rubber bumper is usually modeled by linear spring-dashpot elements [16, 17]; the two parameters, $k_{p}$ and $c_{p}$, of the spring-dashpot elements are determined in the literature $[16,17]$. The stiffness $k_{p}$ of a single device depends on its dimensions and can be calculated from the formula:

$$
k_{p}=\frac{E_{r} A_{p}}{t_{p}},
$$

where $A_{p}$ is a cross-sectional area of the pad, $t_{p}$ is its thickness, and $E_{r}$ is the Young modulus of the rubber. On the other hand, the bumper's damping, $c_{p}$, can be computed as

$$
c_{p}=2 \xi \sqrt{k_{p} \frac{m_{s}}{2}}
$$

where $\xi$ is a damping ratio of the rubber and $m_{s}$ is a mass of the superstructure segment.

The pounding between the high-damping rubber bumper and the superfloor above the isolation system in Figure 1 is simulated by the Kelvin impact elements of the springdashpot type. In these Kelvin impact elements, the stiffness $k_{p}$, the bumper's damping $c_{p}$, and gap $d_{u}$ represent the restoring force owed to rubber compression, energy losses incurred during collisions, and reserve pounding space, respectively. Given that the linear spiral spring begins its function of limiting deformation before collision, mechanical models of the protective system can be established, as shown in Figure 2.

According to the mechanical model, the restoring force of the protective system for right-sided limiting deformation is expressed as follows:

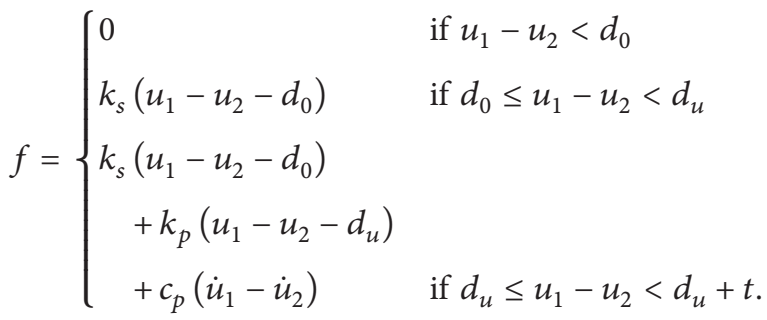

The restoring force of the protective system for left-sided limiting deformation is also given by

$f= \begin{cases}0 & \text { if } u_{1}-u_{2}>-d_{0} \\ k_{s}\left(u_{1}-u_{2}+d_{0}\right) & \text { if }-d_{u}<u_{1}-u_{2} \leq-d_{0} \\ k_{s}\left(u_{1}-u_{2}+d_{0}\right) & \\ +k_{p}\left(u_{1}-u_{2}+d_{u}\right) & \\ +c_{p}\left(\dot{u}_{1}-\dot{u}_{2}\right) & \text { if }-\left(d_{u}+t\right)<u_{1}-u_{2} \leq-d_{u},\end{cases}$

where $u_{1}$ and $u_{2}$ are the displacements of endpoint $E_{1}$ and $E_{2}$ of the mechanical model, and they also represent the displacements of the super-floor above isolation system and the sub-floor below isolation system respectively, and $t$ is the amount of compression of high-damping rubber.

If the energy losses incurred during collisions are not taken into account; in particular, assuming that the coefficient of restitution $e=1$, and the protective systems can be simplified as stiffness variable protective systems. The forcedisplacement curve of the devices is illustrated in Figure 3, in which $u_{b}=u_{1}-u_{2}$. 


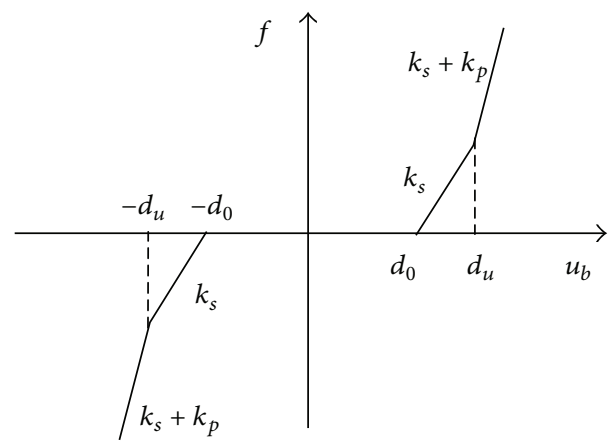

FiguRE 3: Force-displacement curve of protective systems.

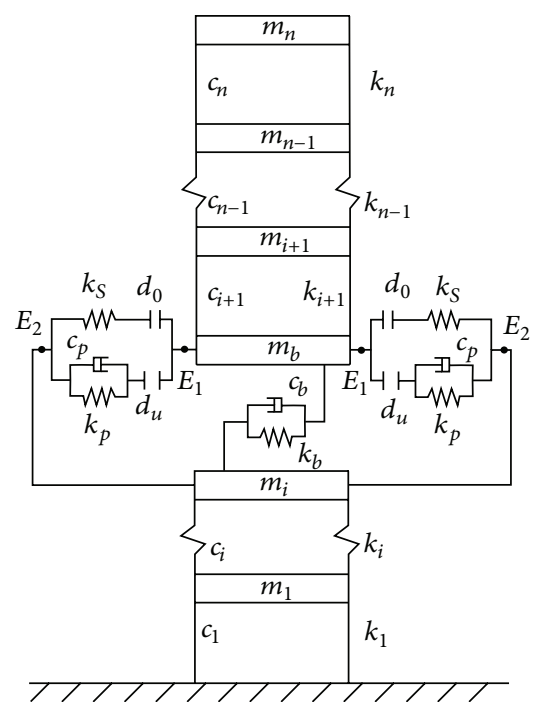

FIGURE 4: Mechanical model of a midstory isolated building with protective systems.

\section{Mechanical Model for Midstory Isolation with a Protective System and Its Equations of Motion}

In current practice, the preliminary design of midstory isolated buildings usually follows the equivalent lateral force procedure provided for base-isolated buildings, assuming that the substructure is sufficiently stiff or rigid. However, the dynamic behavior of a midstory isolated building and a base-isolated building may not be identical since the seismic responses of a midstory isolated building may be significantly affected by the substructure's flexibility, for example, the first story. Furthermore, the interaction between the superstructure and substructure may not be negligible; therefore, a nonlinear response analysis for the final design check should be required. A mechanical model of a midstory isolated building with protective systems can be established, as shown in Figure 4.

In the model, $m_{b}, k_{b}$, and $c_{b}$ are the mass, stiffness, and damping of isolation layer, respectively. $m_{i}, k_{i}$, and $c_{i}$ $(i=1,2, \ldots, n)$ are the mass, stiffness, and damping of the other story, respectively, corresponding to those parameters of the original aseismic structure. The parameters of the protective system were depicted in the previous section.

4.1. Equations of Motion without Soft Pounding. The protective system for limiting the deformation of the isolation layer will not work when the linear spiral spring does not collide with the upper-floor above the isolation system. Accordingly, the equations of motion for the midstory isolated building with a protective system are the same as those without a protective system. Under the condition that the story yield strength is relatively small, the superstructure and substructure generate plastic hysteretic deformations as well as isolation bearings under near-field pulse-like ground motion. The interstory restoring force model in the nonlinear hysteretic system can be determined by Wen [18]. The interstory restoring force of the $i$ th story is expressed as

$$
f_{i}=\alpha_{i} k_{i} y_{i}+\left(1-\alpha_{i}\right) k_{i} z_{i}
$$

where $\alpha_{i}=$ postyielding to preyielding stiffness ratio; $k_{i}=$ interstory elastic stiffness of the $i$ th story; $y_{i}=$ interstory displacement of the $i$ th story; $z_{i}=$ a hysteretic component; and $\dot{z}_{i}=$ time derivative and can be expressed in terms of

$$
\dot{z}_{i}=A_{i} \dot{y}_{i}-\frac{\beta_{i}}{D_{y i}^{n_{i}}}\left|\dot{y}_{i}\right|\left|z_{i}\right|^{n_{i}-1} z_{i}-\frac{r_{i}}{D_{y i}^{n_{i}}} y_{i}\left|v_{i}\right|^{n_{i}},
$$

in which $D_{y i}=$ yield constant displacement and $\beta_{i}, r_{i}, n_{i}$, and $A_{i}=$ nondimensional parameters that govern the shape and size of the hysteresis loop.

The dynamic equation of the motion of the superstructure considering nonlinearity can be formulated as

$$
\begin{aligned}
& {\left[\mathbf{M}^{u}\right]\left\{\ddot{\mathbf{u}}_{u}\right\}+\left[\mathbf{C}^{u}\right]\left\{\dot{\mathbf{u}}_{u}\right\}+\alpha_{u}\left[\mathbf{K}^{u}\right]\left\{\mathbf{u}_{u}\right\} } \\
&+\left(1-\alpha_{u}\right)\left[\mathbf{K}^{u}\right]\left[\mathbf{T}_{u}\right]\left\{\mathbf{z}_{u}\right\} \\
&=-\left[\mathbf{M}^{u}\right]\{\mathbf{I}\}\left\{\ddot{u}_{b}+\{\mathbf{R}\}\left[\left\{\ddot{\mathbf{u}}_{d}\right\}+\left\{\mathbf{I}_{1}\right\} \ddot{u}_{g}\right]\right\},
\end{aligned}
$$

where $\left[\mathbf{M}^{u}\right],\left[\mathbf{K}^{u}\right]$, and $\left[\mathbf{C}^{u}\right]$ are, respectively, the mass matrix, stiffness matrix, and damping matrix of the superstructure. $\left\{\mathbf{u}_{u}\right\},\left\{\dot{\mathbf{u}}_{u}\right\}$, and $\left\{\ddot{\mathbf{u}}_{u}\right\}$, respectively, denote the displacement, velocity, and acceleration of the superstructure relative to the superfloor above isolation system. $\ddot{u}_{b}$ is the acceleration of the superfloor above the isolation system relative to the subfloor below isolation system, $\left\{\ddot{\mathbf{u}}_{d}\right\}$ is the acceleration of the substructure relative to ground, and $\ddot{u}_{g}$ is ground acceleration. $\left\{\mathbf{z}_{u}\right\}$ are hysteretic components of the superstructure. $\{\mathbf{R}\}$ is a position vector of earthquake effect; namely, $\{\mathbf{R}\}=$ $\left\{\begin{array}{llll}0 & 0 & \cdots & 1\end{array}\right\} .\{\mathbf{I}\}$ and $\left\{\mathbf{I}_{1}\right\}$ are the $n-i$ order and $i$ order unit columns. $\mathbf{T}_{i}$ is a transform matrix of hysteretic components. The superscript and subscript $(u, b$, or $d)$ represent the superstructure, isolation layer, and substructure.

The equation of motion of isolation layer is given by:

$$
\begin{aligned}
m_{b} \ddot{u}_{b}= & -\{\mathbf{I}\}^{\mathbf{T}}\left[\mathbf{M}^{u}\right]\left\{\{\mathbf{I}\}\left[\ddot{u}_{b}+\{\mathbf{R}\}\left(\left\{\ddot{\mathbf{u}}_{d}\right\}+\left\{\mathbf{I}_{1}\right\} \ddot{u}_{g}\right)\right]+\left\{\ddot{\mathbf{u}}_{u}\right\}\right\} \\
& -m_{b}\{\mathbf{R}\}\left(\left\{\ddot{\mathbf{u}}_{d}\right\}+\left\{\mathbf{I}_{1}\right\} \ddot{u}_{g}\right)-F_{b},
\end{aligned}
$$


where $m_{b}$ is the mass of the isolation layer and $F_{b}$ is a horizontal restoring force generated by isolation bearings in isolation layer.

The dynamic equation of motion of the substructure involving nonlinearity can be developed in the form of

$$
\begin{aligned}
& {\left[\mathbf{M}^{d}\right]\left\{\ddot{\mathbf{u}}_{d}\right\}+\left[\mathbf{C}^{d}\right]\left\{\dot{\mathbf{u}}_{d}\right\}+\alpha_{d}\left[\mathbf{K}^{d}\right]\left\{\mathbf{u}_{d}\right\} } \\
&+\left(1-\alpha_{d}\right)\left[\mathbf{K}^{d}\right]\left[\mathbf{T}_{d}\right]\left\{\mathbf{z}_{d}\right\} \\
&=- {\left[\mathbf{M}^{d}\right]\left\{\mathbf{I}_{1}\right\} \ddot{u}_{g}-\{\mathbf{R}\}^{\mathbf{T}} } \\
& \cdot\left\{\left(\{\mathbf{I}\}^{\mathbf{T}}\left[\mathbf{M}^{u}\right]\{\mathbf{I}\}+m_{b}\right)\right. \\
&\left.\cdot\left[\ddot{u}_{b}+\{\mathbf{R}\}\left(\left\{\ddot{\mathbf{u}}_{d}\right\}+\left\{\mathbf{I}_{1}\right\} \ddot{u}_{g}\right)\right]+\{\mathbf{I}\}^{\mathbf{T}}\left[\mathbf{M}^{u}\right]\left\{\ddot{\mathbf{u}}_{u}\right\}\right\},
\end{aligned}
$$

where $\left[\mathbf{M}^{d}\right],\left[\mathbf{K}^{d}\right]$, and $\left[\mathbf{C}^{d}\right]$ are, respectively, the mass matrix, stiffness matrix, and damping matrix of the substructure. $\left\{\mathbf{u}_{d}\right\}$ and $\left\{\dot{\mathbf{u}}_{d}\right\}$ are the displacement and velocity of the substructure relative to ground. $\left\{\mathbf{z}_{d}\right\}$ are hysteretic components of the substructure.

4.2. Equations of Motion with Right-Sided Soft Pounding. The equations of motion for the superstructure and substructure in the process of right-sided soft pounding are the same as (10) and (12).

When $d_{0} \leq u_{b}<d_{u}$, the superfloor above the isolation system collides with the right-sided linear spiral spring; the equation of motion for the isolation layer can be obtained as follows:

$$
\begin{aligned}
m_{b} \ddot{u}_{b} & +k_{s}\left(u_{b}-d_{0}\right) \\
= & -\left\{\mathbf{I}^{\mathrm{T}}\left[\mathbf{M}^{u}\right]\left\{\{\mathbf{I}\}\left[\ddot{u}_{b}+\{\mathbf{R}\}\left(\left\{\ddot{\mathbf{u}}_{d}\right\}+\left\{\mathbf{I}_{1}\right\} \ddot{u}_{g}\right)\right]+\left\{\ddot{\mathbf{u}}_{u}\right\}\right\}\right. \\
& -m_{b}\{\mathbf{R}\}\left(\left\{\ddot{\mathbf{u}}_{d}\right\}+\left\{\mathbf{I}_{1}\right\} \ddot{u}_{g}\right)-F_{b},
\end{aligned}
$$

where $u_{b}$ is the displacement of the superfloor above the isolation system relative to the subfloor below the isolation system.

When $d_{u} \leq u_{b}<d_{u}+t$, the superfloor above the isolation system collides with the right-sided high-damping rubber bumper, and the equation of motion of isolation layer can be expressed as

$$
\begin{aligned}
m_{b} \ddot{u}_{b} & +k_{s}\left(u_{b}-d_{0}\right)+k_{p}\left(u_{b}-d_{u}\right)+c_{p} \dot{u}_{b} \\
= & -\{\mathbf{I}\}^{\mathbf{T}}\left[\mathbf{M}^{u}\right]\left\{\{\mathbf{I}\}\left[\ddot{u}_{b}+\{\mathbf{R}\}\left(\left\{\ddot{\mathbf{u}}_{d}\right\}+\left\{\mathbf{I}_{1}\right\} \ddot{u}_{g}\right)\right]+\left\{\ddot{\mathbf{u}}_{u}\right\}\right\} \\
& -m_{b}\{\mathbf{R}\}\left(\left\{\ddot{\mathbf{u}}_{d}\right\}+\left\{\mathbf{I}_{1}\right\} \ddot{u}_{g}\right)-F_{b},
\end{aligned}
$$

where $\dot{u}_{b}$ is the velocity of the superfloor above the isolation system relative to the subfloor below the isolation system.

4.3. Motion Equation with Left-Sided Soft Pounding. In the process of left-sided soft pounding, the equations of motion of the superstructure and substructure are also identical to (10) and (12).

When $-d_{u}<u_{b} \leq-d_{0}$, the superfloor above the isolation system collides with the left-sided linear spiral spring, and the equation of motion for isolation layer can be given by

$$
\begin{aligned}
m_{b} \ddot{u}_{b} & -k_{s}\left(u_{b}+d_{0}\right) \\
= & -\{\mathbf{I}\}^{\mathbf{T}}\left[\mathbf{M}^{u}\right]\left\{\{\mathbf{I}\}\left[\ddot{u}_{b}+\{\mathbf{R}\}\left(\left\{\ddot{\mathbf{u}}_{d}\right\}+\left\{\mathbf{I}_{1}\right\} \ddot{u}_{g}\right)\right]+\left\{\ddot{\mathbf{u}}_{u}\right\}\right\} \\
& -m_{b}\{\mathbf{R}\}\left(\left\{\ddot{\mathbf{u}}_{d}\right\}+\left\{\mathbf{I}_{1}\right\} \ddot{u}_{g}\right)-F_{b} .
\end{aligned}
$$

When $-\left(d_{u}+t\right)<u_{b} \leq-d_{u}$, the superfloor above the isolation system collides with the left-sided high-damping rubber bumper, and the equation of motion for the isolation layer can be formulated as

$$
\begin{aligned}
m_{b} \ddot{u}_{b} & -k_{s}\left(u_{b}+d_{0}\right)-k_{p}\left(u_{b}+d_{u}\right)-c_{p} \dot{u}_{b} \\
= & -\left\{\mathbf{I}^{\mathbf{T}}\left[\mathbf{M}^{u}\right]\left\{\{\mathbf{I}\}\left[\ddot{u}_{b}+\{\mathbf{R}\}\left(\left\{\ddot{\mathbf{u}}_{d}\right\}+\left\{\mathbf{I}_{1}\right\} \ddot{u}_{g}\right)\right]+\left\{\ddot{\mathbf{u}}_{u}\right\}\right\}\right. \\
& -m_{b}\{\mathbf{R}\}\left(\left\{\ddot{\mathbf{u}}_{d}\right\}+\left\{\mathbf{I}_{1}\right\} \ddot{u}_{g}\right)-F_{b} .
\end{aligned}
$$

\section{Synthesis of Artificial Near-Field Pulse-Like Ground Motion}

Near-field ground motion is featured by long-period horizontal pulses, high values of the ratio between the peak value of velocity (PGV) and the peak value of acceleration (PGA), which may trigger serious structural damage [10]. The value of PGV/PGA and the distance to the fault rupture are major factors that need to be taken into account to identify whether near-field ground motions are pulse-like or nonpulse. When the value of PGV/PGA is greater than 0.2 and the distance to the fault rupture is within $20 \mathrm{~km}$, nearfield ground motion is pulse-like and would exert notable pulse effects on structures [19]. Artificial near-field pulse-like ground motions need to be generated in order to facilitate the investigation of the effects of characteristic parameters associated with near-field pulse-like ground motion, such as pulse type, pulse contribution factor, and pulse period, on midstory isolated structures.

5.1. Equivalent Pulse Model of Velocity. Dicleli and Buddaram [20] presented the equivalent pulse model of velocity, which could be used to analyze the parameter effects of near-field ground motion on responses of civil structures. The velocity time histories of the ground motion are given by the following equation:

$$
\dot{v}_{p}(t)=s e^{-\xi_{p} \omega_{p} t} \sin \left(\omega_{p} \sqrt{1-\xi_{p}^{2}} t\right),
$$

where $\xi_{p}$ is the decaying factor (similar to the damping factor in structural dynamics problems) of the sinusoid, $\omega_{p}$ is the frequency of the sinusoid, $s$ is the initial amplitude of the velocity pulse, and $t$ is the time in seconds. The decaying 


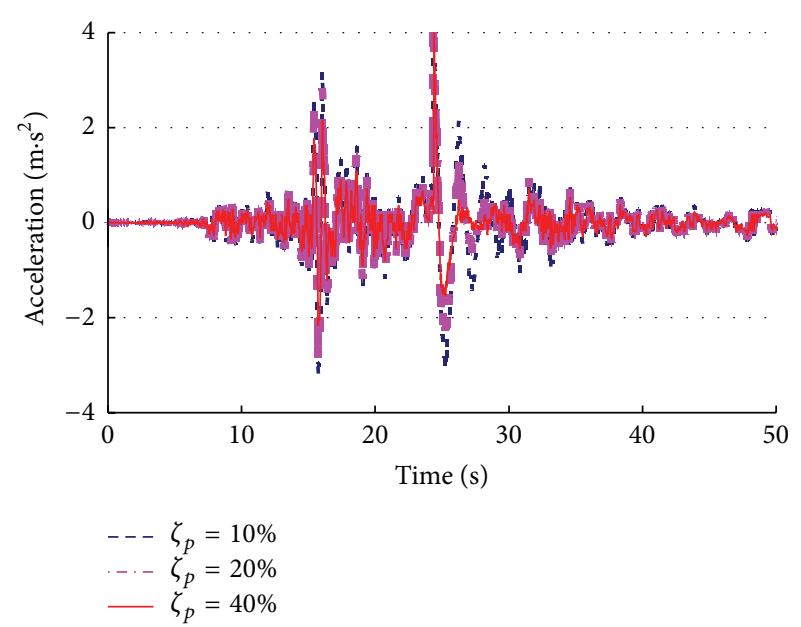

(a)

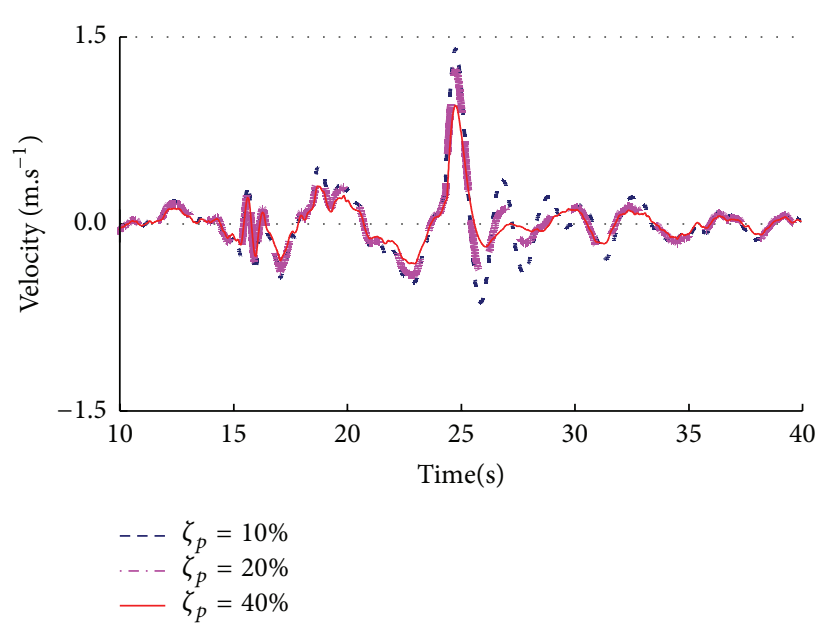

(b)

Figure 5: Simulated near-field pulse-like ground motion with various decaying factors to reproduce different numbers of pulses. (a) Time history of pulse acceleration; (b) time history of pulse velocity.

sinusoids with $\xi_{p}=10 \%, 20 \%$, and $40 \%$ resemble near-fault ground motion with multiple, forward-and-backward, and forward velocity pulses, since increasing values of $\xi_{p}$ from $10 \%$ to $20 \%$ and to $40 \%$ result in only three, two, and one significant pulse(s), respectively.

To simulate a near-fault ground motion with a peak ground velocity $V_{p}$, a pulse period $T_{p}$, and a decaying factor $\xi_{p}$, the model parameters $s$ and $\omega_{p}$ must be chosen such that the peak velocity and pulse period of the model match the given $V_{p}$ and $T_{p}$. For this purpose, $s$ and $\omega_{p}$ are calculated by the following equations:

$$
\begin{gathered}
\omega_{p}=\frac{2 \pi}{T_{p} \sqrt{1-\xi_{p}^{2}}}, \\
t_{p}=\frac{\tan ^{-1}\left(\sqrt{1 / \xi_{p}^{2}-1}\right)}{\omega_{p} \sqrt{1-\xi_{p}^{2}}}, \\
s=\frac{V_{p}}{e^{-\xi_{p} \omega_{p} t_{p}} \sin \omega_{p} \sqrt{1-\xi_{p}^{2}} t_{p}} .
\end{gathered}
$$

5.2. Simulation of Near-Field Pulse-Like Ground Motion. The idea of synthesizing ground motion presented by Park et al. [21] can also be utilized to simulate pulse-like effects of nearfield ground motion. Through introducing pulse contributing factor $\beta$, artificial near-field pulse-like ground motion can be synthesized by combining the above-mentioned simple equivalent pulse model with real near-field nonpulse ground motion, rather than far-field ground motion. Through this method, the effects of velocity pulses and high frequency components of the near-field site can be taken into account to avoid the difference of spectrum characteristics caused by adopting far-field ground motion in the simulation. Such artificially generated near-field ground motion facilitates revealing the impacts of various pulse types, pulse contributing factor $\beta$, and pulse periods on midstory isolated structures and, further, performing a comparative analysis of pulse-like and nonpulse ground movements on midstory isolated structures.

The velocity time history of the artificial generated nearfield pulse-like ground motion is expressed as

$$
\dot{v}_{g}(t)=\dot{v}_{g, b}(t)+\beta \cdot \dot{v}_{p}(t),
$$

where $\dot{v}_{g, b}(t)$ is the velocity time history of the near-field nonpulse ground motion and $\beta$ is the pulse contributing factor. When the value increases, the effect of the velocity pulse will become more significant. In the process of synthesis, the corresponding time of the peak pulse velocity of $\dot{v}_{p}(t)$ is adjusted to coincide with that of the nonpulse peak velocity of $\dot{v}_{g, b}(t)$. Afterward, the pulse-like acceleration time history of the artificially generated ground motion is finally obtained via the derivation of the above-mentioned artificial velocity time history.

To examine the effects of characteristic parameters associated with near-field ground motion on nonlinear seismic responses of midstory isolated structures, artificial near-field pulse-like ground motion is simulated by combining the above-mentioned equivalent velocity pulse with CHY029N, which is a near-field nonpulse velocity component of the 1999 Chi-Chi earthquake in Taiwan. It should be noted that the value of PGV/PGA for CHY029-N is equal to 0.15 for $\mathrm{PGV}=35.2 \mathrm{~cm} / \mathrm{s}$ and $\mathrm{PGA}=238 \mathrm{~cm} / \mathrm{s}^{2}$, and the distance to fault rupture is $15.2 \mathrm{~km}$. Figure 5 describes the velocity and acceleration time histories of a simulated near-field pulse-like ground motion with different decaying factors $\xi_{p}$, assuming the pulse contributing factor $\beta=2$. In the figure, the value of peak ground acceleration has been scaled to $400 \mathrm{~cm} / \mathrm{s}^{2}$, and the value of peak ground velocity is also correspondingly adjusted.

The figure shows that the decaying factors with $\xi_{p}=$ $10 \%, 20 \%$, and $40 \%$ resemble near-fault ground motion with 
TABLE 1: Main characteristics of lead-rubber bearing.

\begin{tabular}{lccccccc}
\hline $\begin{array}{l}\text { Bearing } \\
\text { type }\end{array}$ & $\begin{array}{c}\text { Allowable } \\
\text { deformation }(\mathrm{m})\end{array}$ & $\begin{array}{c}\text { Vertical stiffness } \\
(\mathrm{kN} / \mathrm{m})\end{array}$ & $\begin{array}{c}\text { Preyield } \\
\text { stiffness }(\mathrm{kN} / \mathrm{m})\end{array}$ & $\begin{array}{c}\text { Postyield } \\
\text { stiffness }(\mathrm{kN} / \mathrm{m})\end{array}$ & $\begin{array}{c}\text { Yield } \\
\text { force }(\mathrm{kN})\end{array}$ & $\begin{array}{c}\text { Equivalent } \\
\text { damping ratio }\end{array}$ & $\begin{array}{c}\text { Equivalent } \\
\text { stiffness }(\mathrm{kN} / \mathrm{m})\end{array}$ \\
\hline GZY700 & 0.385 & 2614000 & 6519 & 1003 & 94.2 & $27.2 \%$ & 1859 \\
\hline
\end{tabular}

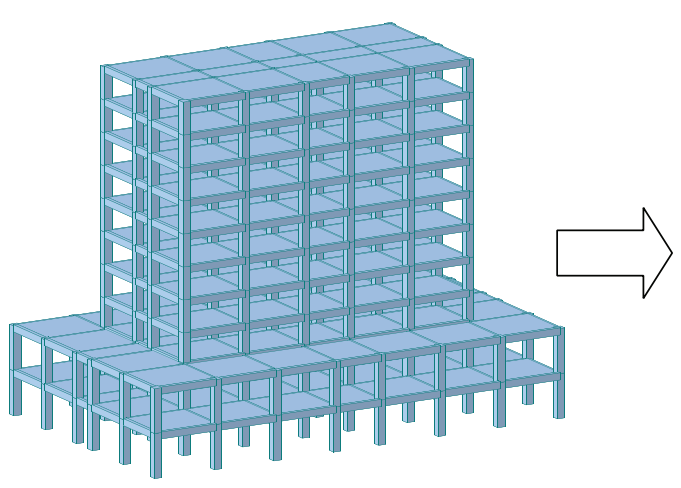

(a)

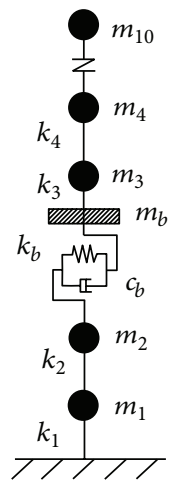

(b)

FIgURE 6: Midstory isolated test structure. (a) Structural model; (b) simplified mechanical model.

multiple, forward-and-backward, and forward velocity and acceleration pulses, since increasing values of $\xi_{p}$ from $10 \%$ to $20 \%$ and to $40 \%$ result in only three, two, and one significant pulse(s), respectively. As observed from Figure 5(b), the amplitude of the peak velocity is affected by the decaying factors and decreases with the increase of decaying factors.

Near-field pulse-like ground motion contains longperiod velocity pulses as well as high frequency components of near-field sites, which make conventional seismic isolation design difficult. This is because long-period velocity pulses intensify the isolated structure's seismic responses even if the fundamental period of the isolated structure is increased to prevent destruction caused by high frequency components and high peak acceleration.

\section{Effects of Near-Field Ground Motion on Nonlinear Dynamic Responses of Midstory Isolation}

6.1. Selection of Structure Parameters. We have taken into consideration a demonstration of the effects of characteristic parameters associated with near-field ground motion on the nonlinear seismic response of a midstory isolated test structure and then examined the validation of the proposed protective system to limit the excessive deformation of the isolation layer. This test structure is a 10 -story building with a 2-story large podium at the bottom and the height is $3.3 \mathrm{~m}$ for each floor, as shown in Figure 6(a). The isolation system consists of 24 similar lead-rubber bearings located on the top of the podium building. The isolators' specifications are described in Table 1.

The midstory isolated test structure is simplified as a mechanical model, as shown in Figure 6(b). In this mechanical model, the floor masses are $m_{1}=1.0 \times 10^{6} \mathrm{~kg}, m_{2}=0.87 \times$ $10^{6} \mathrm{~kg}, m_{b}=3.5 \times 10^{5} \mathrm{~kg}, m_{i}=4.2 \times 10^{5} \mathrm{~kg}(i=3, \ldots, 9)$, and $m_{10}=3.5 \times 10^{5} \mathrm{~kg}$. The story stiffness is $k_{1}=k_{2}=$ $0.7 \times 10^{7} \mathrm{kN} / \mathrm{m}$ and $k_{i}=0.52 \times 10^{7} \mathrm{kN} / \mathrm{m}(i=3, \ldots, 10)$. The fundamental periods of the fixed-base structure and the midstory isolated structure are $1.12 \mathrm{~s}$ and $3.2 \mathrm{~s}$. The interstory restoring force of the $i$ th story can be calculated by (8)-(9). In these equations, the yield constant displacement $D_{y i}(i=$ $1,2)=1.5 \mathrm{~cm}, D_{y i}(i=3, \ldots, 10)=1.2 \mathrm{~cm}, A=\beta=r=1$, $\alpha=0.3$, and $n_{i}=95$, respectively.

The protective systems for limiting deformation have been installed at both sides of the isolated story, and its mechanical model is shown in Figure 4. The corresponding dynamic analysis program is compiled using Matlab language for numerical analysis, in which the method of variable-step four-order Runge-Kutta is applied to perform the time history analyses.

6.2. Effects of Velocity Pulse Type. In order to investigate impacts of velocity pulse type on the midstory isolated structure, the artificial pulse-like ground motion was simulated using the values of characteristic parameters (i.e., $\beta=4$, $T_{b}=1.97 \mathrm{~s}$, and $\left.V_{p}=35.2 \mathrm{~cm} / \mathrm{s}\right)$. It has been noted that the value of peak ground acceleration was scaled to $400 \mathrm{~cm} / \mathrm{s}^{2}$ herein and in the other parts of Section 6. Seismic responses of the isolated structure under near-field ground motion with multiple, forward-and-backward, and forward velocity pulses are shown in Figure 7.

As observed in Figure 7(a), peak displacements of the superstructure under near-field pulse-like ground motion increased when compared with those under nonpulse ground motion. Deformations of the isolation layer increased significantly and exceeded the allowable deformation of isolation bearings. In particular, the value of the maximum deformation of isolation layer under a multiple velocity pulse reached $74.8 \mathrm{~cm}$ and is 1.94 times as much as that of the allowable deformation of isolation bearings. In addition, Figure 7(b) 


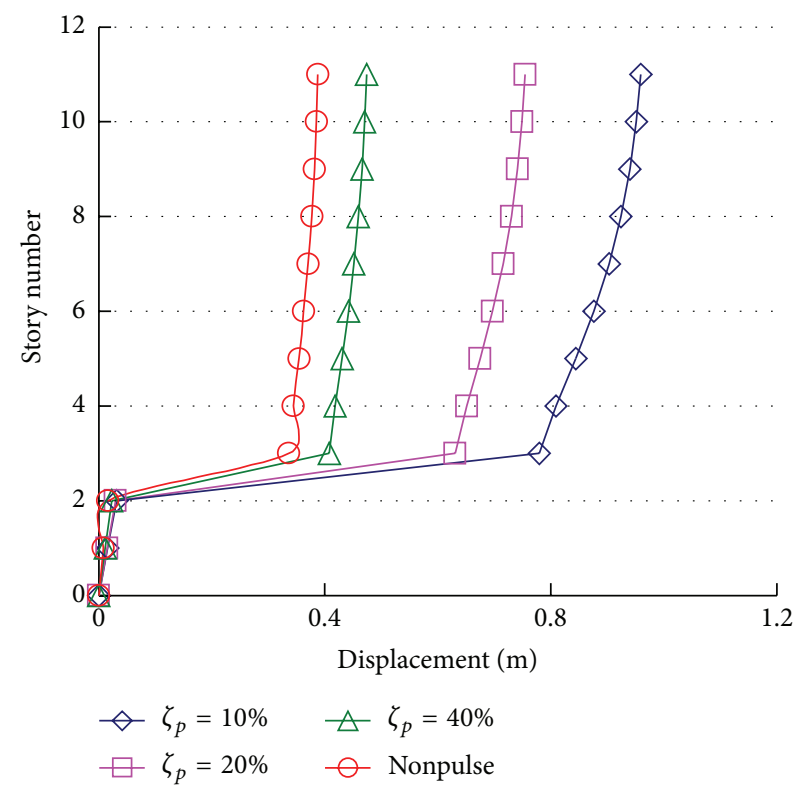

(a)

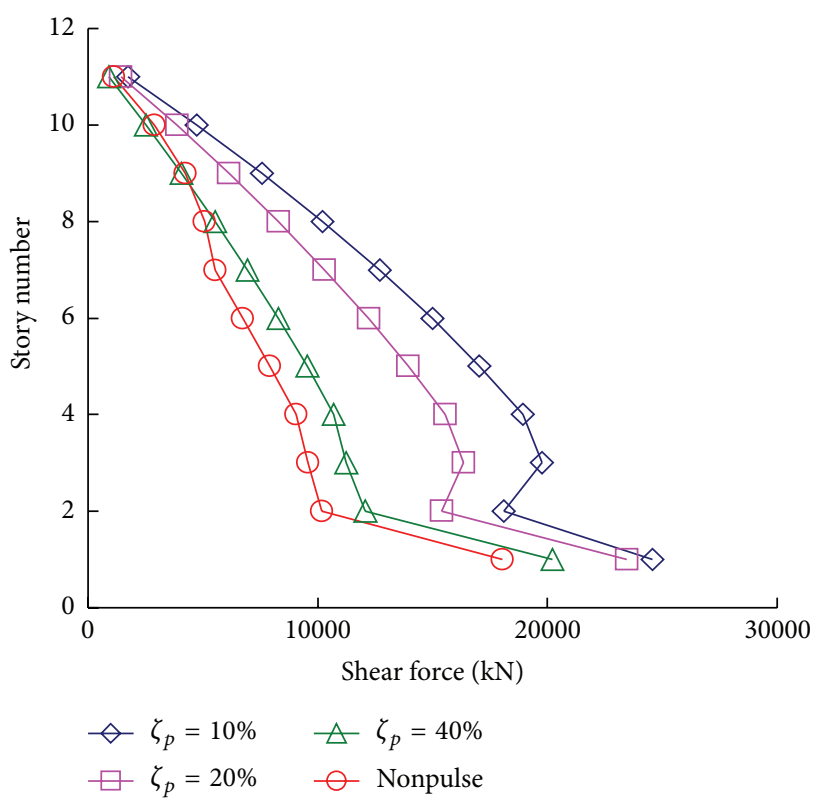

(b)

FIGURE 7: Responses of the midstory isolated structure under different types of near-field pulse-like ground motion. (a) Peak displacement along height of building; (b) peak shear force along height of building.

indicated that shear forces of stories significantly increased under near-field pulse-like ground motion when compared with those under nonpulse ground motion, especially when the maximum shear force increased by up to $130 \%$ under a multiple velocity pulse.

It is also shown in Figure 7 that peak displacements and peak shear forces of stories decrease with the increase of decaying factors $\xi_{p}$, especially in the superstructure.

6.3. Effects of the Pulse Contribution Factor. To investigate effects of pulse contribution factor $\beta$ on the midstory isolated structure, the artificial pulse-like ground motion was generated with the values of characteristic parameters (i.e., $\xi_{p}=0.2, T_{b}=1.97 \mathrm{~s}$, and $\left.V_{p}=35.2 \mathrm{~cm} / \mathrm{s}\right)$. Figure 8 illustrates effects of various pulse contributing factors $\beta$ on dynamic responses of the midstory isolated structure.

The results in Figure 8 show that as pulse contribution factor $\beta$ increases, the peak displacements and peak shear forces of stories increase, while this tendency weakens slowly.

All of the peak displacements and peak shear forces were greater than those under the nonpulse ground motion. In particular, the deformation of the isolation layer increased remarkably in comparison with that subjected to nonpulse ground motion and greatly exceeded the allowable deformation of the isolation bearings.

6.4. Effects of Velocity Pulse Period. Figure 9 shows the effects of velocity pulse periods on dynamic responses of the midstory isolated structure, where the characteristic parameters of pulse-like ground motions were selected as $\beta=1, \xi_{p}=0.2$, and $V_{p}=35.2 \mathrm{~cm} / \mathrm{s}$.
From Figure 9, it can be seen that the peak shear force and peak plastic interstory drift ratio increased as the velocity pulse period also increased. Noting that there existed a turning point, the velocity pulse period $T_{p}$ had little influence on the responses of the isolated structure when it exceeded this turning point. It also can be observed that velocity pulse periods have more influence on the superstructure's responses than on the responses of the substructure.

Effects of various $T_{p}$ on the maximum deformation of the isolation layer are depicted in Figure 10. From the figure, it is evident that the maximum deformation of the isolation layer increased with the increase of the velocity pulse period and $T_{p}$ demonstrated little influence on the maximum deformation when it exceeded the turning point. Additionally, the maximum deformation of the isolation layer apparently exceeded the permissible deformation of lead-rubber bearings, which would destroy the isolation bearings and further lead to the overturning collapse of the superstructure.

\section{Analysis on the Seismic Performance of Midstory Isolation with Protective Systems}

As shown in Table 2, actual near-field pulse-like ground motion and nonpulse ground motion recorded at Imperial Valley (1979) and Chi-Chi (1999) have been taken into consideration in the analysis of seismic performance of the midstory isolated structure with the proposed protective system. The corresponding main data are available in the Pacific Earthquake Engineering Research Center database (http://peer.berkeley.edu/smcat/).

A protective system in which $d_{0}=5 \mathrm{~cm}, k_{s}=10000 \mathrm{kN} /$ $\mathrm{m}, d_{u}=36 \mathrm{~cm}$, and $k_{p}=71000 \mathrm{kN} / \mathrm{m}$ was employed to 


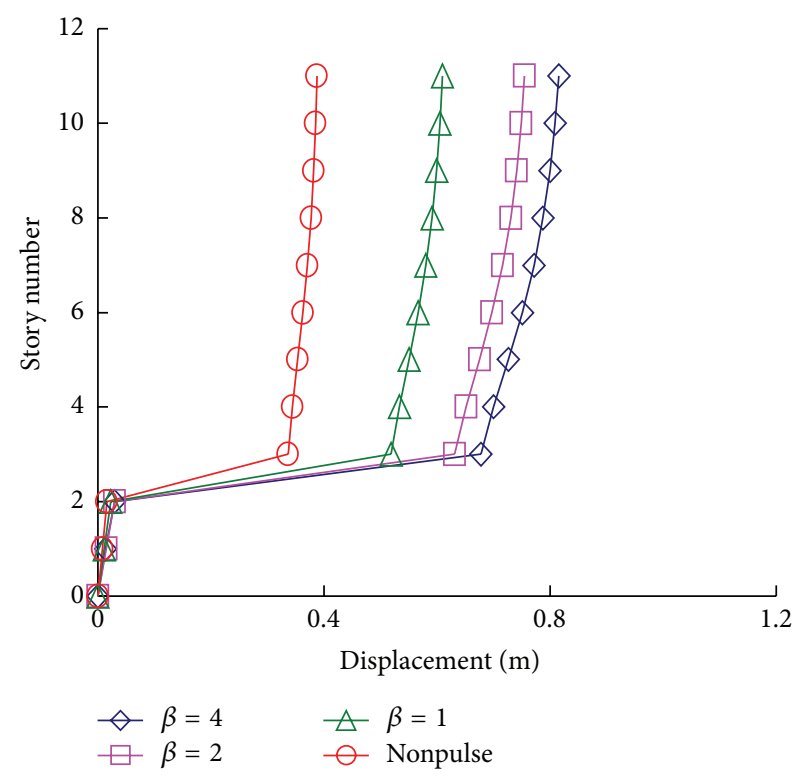

(a)

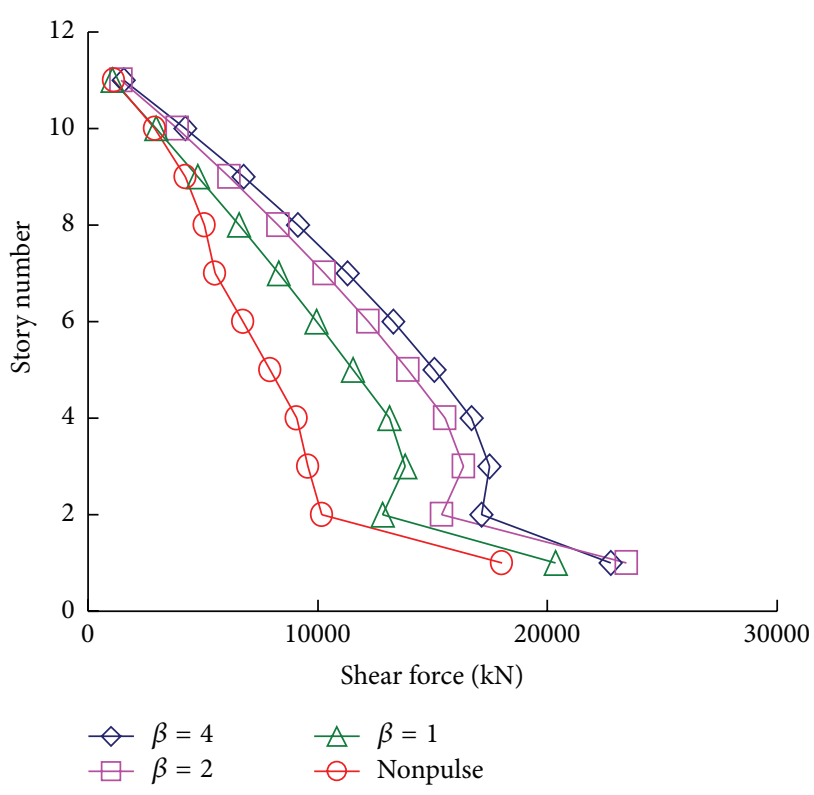

(b)

FIGURE 8: Effects of pulse contributing factor $\beta$ on dynamic responses of the midstory isolated structure. (a) Peak displacement along height of building; (b) peak shear force along height of building.

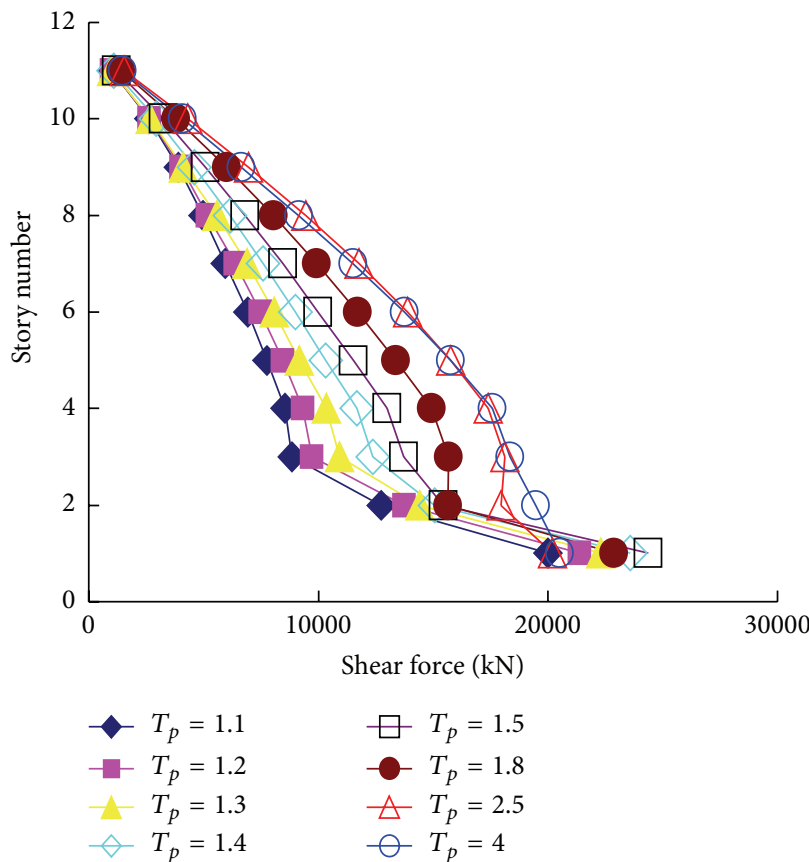

(a)

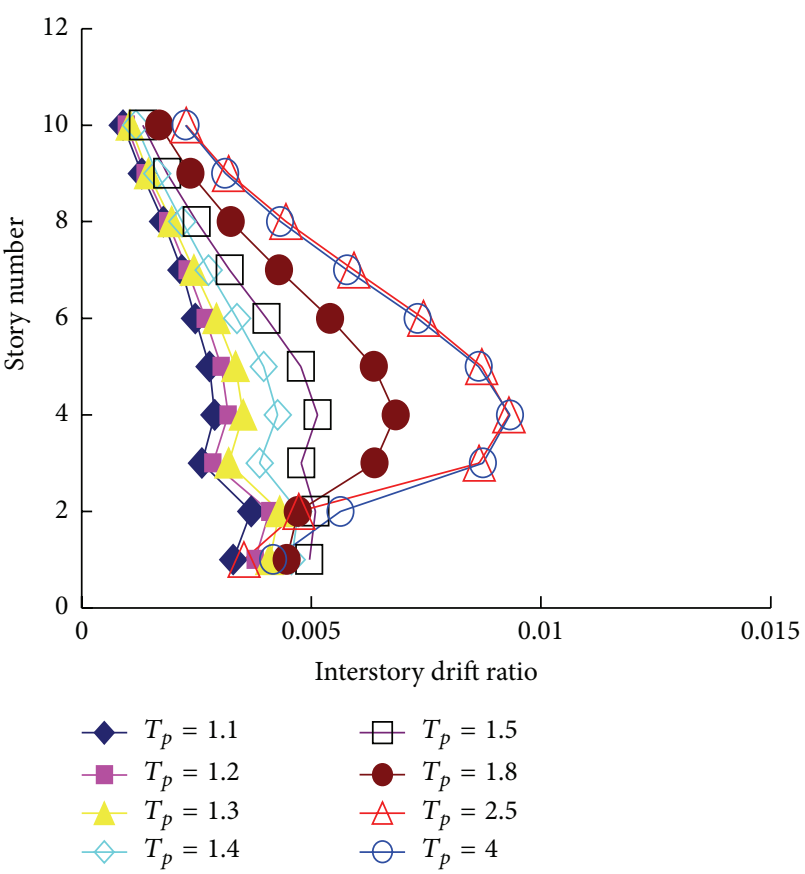

(b)

Figure 9: Effects of $T_{p}$ on dynamic responses of the midstory isolated structure. (a) Peak shear force along height of building; (b) plastic interstory drift ratio.

limit deformation of the isolation layer. Although the energy losses during collisions can be determined using the principle of damping energy equivalence, these energy losses have been ignored for the absence of experimental tests, namely, assuming that coefficient of restitution $e=1$ and damping coefficient $c_{p}=0$.
Table 3 provides a comparison of peak shear forces of seismic resistant structure and midstory isolation under different small earthquake waves, where the values of peak ground accelerations have been scaled to $70 \mathrm{~cm} / \mathrm{s}^{2}$. It was found that the peak shear force and average shear force of the isolated structure with the protective system decreased 
TABLE 2: Ground motion information.

\begin{tabular}{|c|c|c|c|c|c|c|}
\hline Earthquake & $M_{w}$ & Record & PGA $\left(\mathrm{m} / \mathrm{s}^{2}\right)$ & PGV $(\mathrm{m} / \mathrm{s})$ & PGV/PGA (s) & $\begin{array}{c}\text { Distance to fault } \\
\text { rupture }(\mathrm{km})\end{array}$ \\
\hline $\begin{array}{l}\text { Imperial Valley, USA, } \\
15 / 10 / 1979\end{array}$ & 6.5 & HE04230 & 3.60 & 0.766 & 0.22 & 4.2 \\
\hline $\begin{array}{l}\text { Chi-Chi, Taiwan, } \\
\text { 20/9/1999 }\end{array}$ & 7.6 & CHY101W & 3.53 & 0.706 & 0.20 & 11.14 \\
\hline $\begin{array}{l}\text { Chi-Chi, Taiwan, } \\
\text { 20/9/1999 }\end{array}$ & 7.6 & CHY029N & 2.38 & 0.352 & 0.15 & 15.2 \\
\hline $\begin{array}{l}\text { Imperial Valley, USA, } \\
15 / 10 / 1979\end{array}$ & 6.5 & HDLT352 & 3.51 & 0.330 & 0.09 & 43.6 \\
\hline
\end{tabular}

TABLE 3: Comparison of peak shear forces of seismic resistant structure and midstory isolation under different earthquake waves.

\begin{tabular}{lccccccccccc}
\hline $\begin{array}{l}\text { Story } \\
\text { number }\end{array}$ & \multicolumn{3}{c}{$\begin{array}{c}\text { Shear forces of midstory isolation/kN } \\
\text { HE04230 }\end{array}$} & CHY101W & CHY029N & HDLT352 & $\begin{array}{c}\text { Average } \\
\text { value }\end{array}$ & HE04230 & CHY101W & $\begin{array}{c}\text { CHY029N } \\
\text { HDLT352 }\end{array}$ & $\begin{array}{c}\text { Average } \\
\text { value }\end{array}$ \\
\hline 10 & 440 & 253 & 337 & 383 & 353 & 808 & 884 & 856 & 949 & 874 \\
9 & 838 & 598 & 634 & 759 & 707 & 2096 & 2294 & 2169 & 2152 & 2178 \\
8 & 1556 & 1047 & 1310 & 1193 & 1277 & 3094 & 3405 & 3290 & 2786 & 3144 \\
7 & 2188 & 1468 & 1812 & 1607 & 1769 & 3773 & 4193 & 4341 & 3575 & 3971 \\
6 & 1965 & 1562 & 1885 & 1647 & 1765 & 4322 & 4886 & 5270 & 4286 & 4691 \\
5 & 1849 & 1665 & 1835 & 1855 & 1801 & 4944 & 5391 & 6072 & 4874 & 5320 \\
4 & 2348 & 2041 & 2245 & 2020 & 2164 & 5521 & 5522 & 6748 & 5368 & 5790 \\
3 & 4897 & 3164 & 3411 & 3894 & 3842 & 6045 & 5368 & 7322 & 5764 & 6125 \\
2 & 4675 & 3360 & 3375 & 3036 & 3612 & 6955 & 5497 & 8134 & 6812 & 6850 \\
1 & 5484 & 3199 & 3264 & 3945 & 3973 & 8131 & 6140 & 8724 & 7631 & 7657 \\
\hline
\end{tabular}

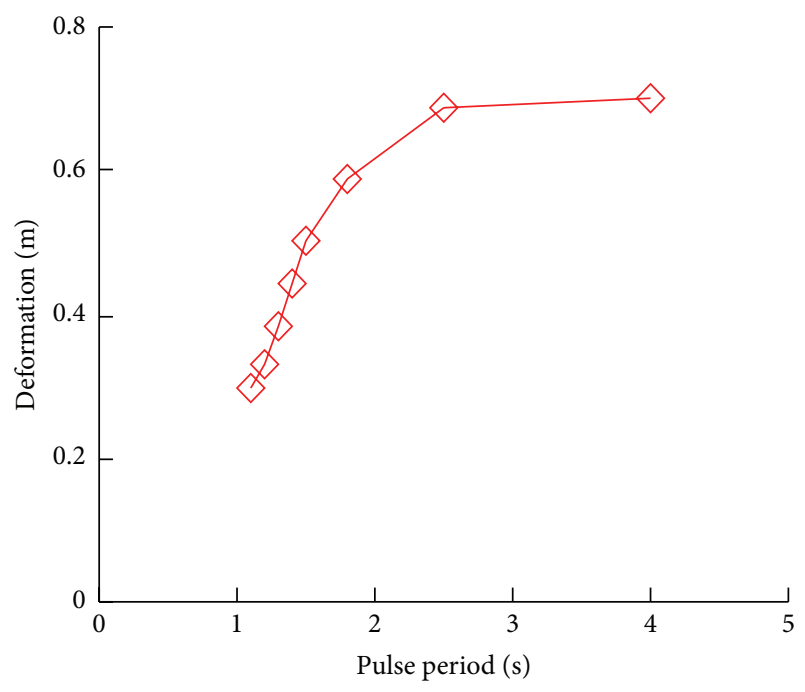

FIGURE 10: Effect of $T_{p}$ on maximum deformation of isolation layer.

dramatically in comparison with those possessing the aseismic structure. Given the results of the numeral analysis, it also can be ascertained that, for the underground motion of HE04230, CHY101W, CHY029N, and HDLT352, the maximum deformation measurements of the isolation layer are
$4.2 \mathrm{~cm}, 2.5 \mathrm{~cm}, 2.7 \mathrm{~cm}$, and $3.2 \mathrm{~cm}$, respectively, and all of them are less than $d_{0}$. This means that the linear spiral spring does not begin its function to limit the deformation of the isolation layer, which is to say that the protective system does not work when subject to small ground motion.

Responses from the aseismic structure and the midisolated structure, both with and without the protective system, were subject to different strong ground movements (PGA = $400 \mathrm{~cm} / \mathrm{s}^{2}$ ), which are shown in Figure 11. As observed in Figure 11(a), when subjected to the pulse-like HE04230 earthquake record, plastic interstory drifts and peak accelerations of the isolated structure with the protective system increased when compared to those without the protective system because the limiting stiffness $k_{s}$ took effect. But take note that the maximum deformations of the isolation layer without the protective system greatly exceed the permissible deformation of lead-rubber bearings, as shown in Table 4, which resulted in the failure of the isolation layer. Thus, the isolation effects without the protective system are imaginary. It has also been indicated that seismic performance of the isolated structure with the protective system was improved, especially in the substructure. Figure 11(b) reveals that when subjected to the nonpulse CHY029N earthquake record, plastic interstory drifts of midisolated structures with and without the protective system decreased and peak accelerations of the superstructure also decreased. Note that the responses of 

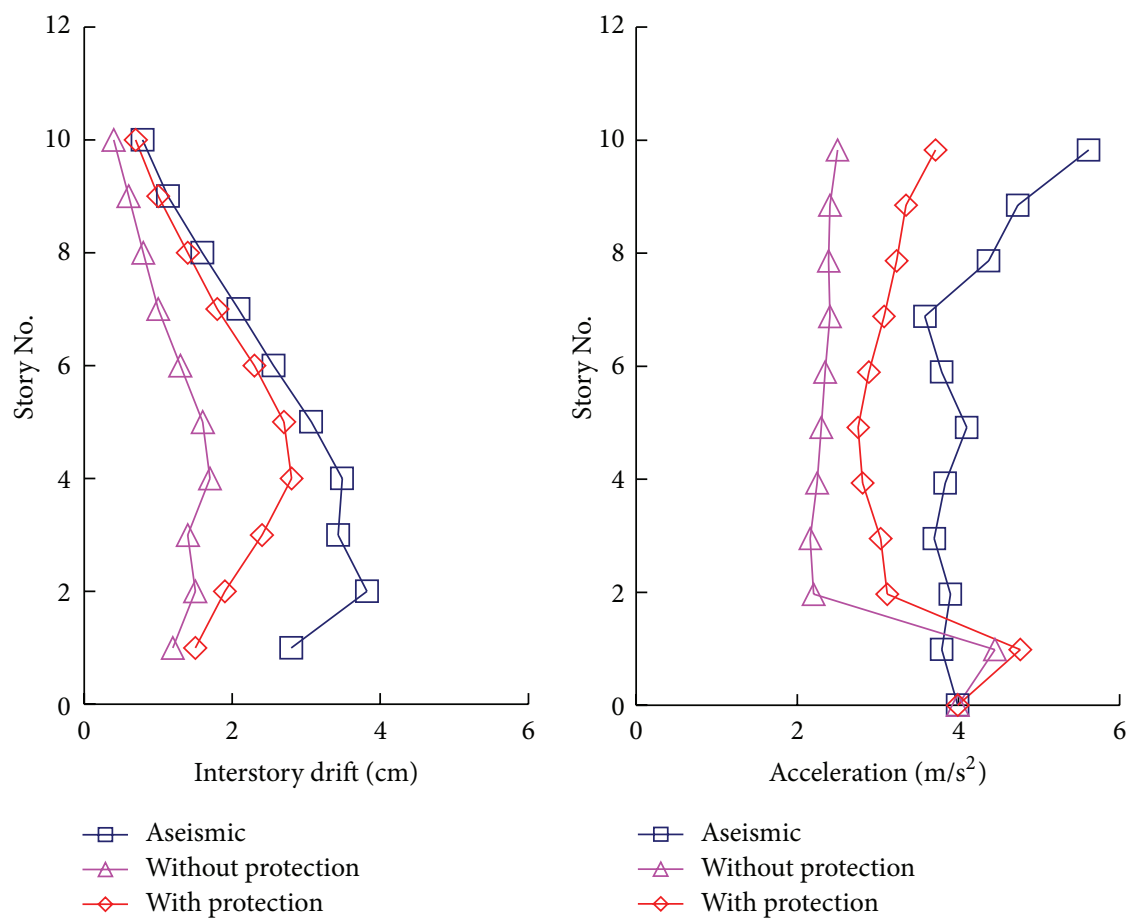

(a) HE04230
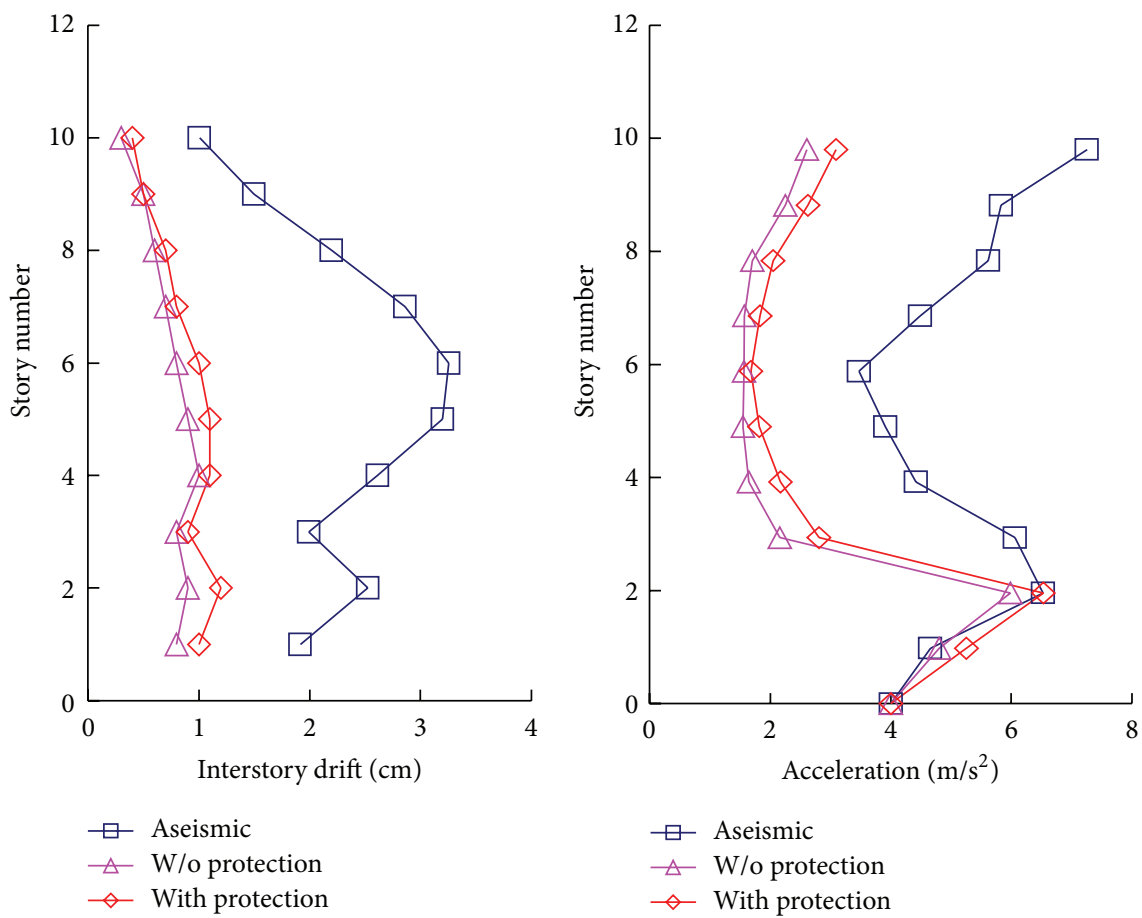

(b) $\mathrm{CHY} 029 \mathrm{~N}$

FIGURE 11: Responses of different structures under different earthquake waves. (a) HE04230; (b) CHY029N.

the midisolated structures with and without the protective system are similar; this means that the protective system has minor influence on the isolated structure.

The comparisons of plastic interstory drifts associated with the midstory isolated structure with and without the protective system are presented in Table 4 , where the values of peak ground accelerations have been scaled to $400 \mathrm{~cm} / \mathrm{s}^{2}$. From Table 4, it can be seen that when subjected to strong pulse-like ground movement, such as the case with HE04230 and CHY101W, plastic interstory drifts of the 
TABLE 4: Comparison of plastic interstory drifts of midstory isolations with and without protective system.

\begin{tabular}{|c|c|c|c|c|c|c|c|c|c|c|}
\hline \multirow{2}{*}{$\begin{array}{l}\text { Story } \\
\text { number }\end{array}$} & \multicolumn{5}{|c|}{ Plastic interstory drifts without protective system $/ \mathrm{cm}$} & \multicolumn{5}{|c|}{ Plastic interstory drifts with protective system $/ \mathrm{cm}$} \\
\hline & HE04230 & CHY101W & CHY029N & HDLT352 & $\begin{array}{c}\text { Limitation } \\
\text { value }(h / 50)\end{array}$ & HE04230 & CHY101W & CHY029N & HDLT352 & $\begin{array}{c}\text { Limitation } \\
\text { value }(h / 50)\end{array}$ \\
\hline 10 & 0.4 & 0.5 & 0.3 & 0.2 & 6.6 & 0.7 & 0.6 & 0.4 & 0.3 & 6.6 \\
\hline 9 & 0.6 & 0.7 & 0.5 & 0.4 & 6.6 & 1.0 & 0.9 & 0.5 & 0.4 & 6.6 \\
\hline 8 & 0.8 & 0.9 & 0.6 & 0.5 & 6.6 & 1.4 & 1.2 & 0.7 & 0.5 & 6.6 \\
\hline 7 & 1.0 & 1.2 & 0.7 & 0.6 & 6.6 & 1.8 & 1.6 & 0.8 & 0.7 & 6.6 \\
\hline 6 & 1.3 & 1.5 & 0.8 & 0.6 & 6.6 & 2.3 & 2.0 & 1.0 & 0.8 & 6.6 \\
\hline 5 & 1.6 & 1.7 & 0.9 & 0.6 & 6.6 & 2.7 & 2.4 & 1.1 & 0.9 & 6.6 \\
\hline 4 & 1.7 & 1.8 & 1.0 & 0.6 & 6.6 & 2.8 & 2.6 & 1.1 & 0.9 & 6.6 \\
\hline 3 & 1.4 & 1.5 & 0.8 & 0.5 & 6.6 & 2.4 & 2.2 & 0.9 & 0.7 & 6.6 \\
\hline $\begin{array}{l}\text { Isolation } \\
\text { layer }\end{array}$ & 50.9 & 49.5 & 32.6 & 16.1 & 38.5 & 35.0 & 35.6 & 21.2 & 15.0 & 38.5 \\
\hline 2 & 1.5 & 1.4 & 0.9 & 1.0 & $3.3(h / 100)$ & 1.9 & 2.1 & 1.2 & 1.0 & $3.3(h / 100)$ \\
\hline 1 & 1.2 & 1.1 & 0.8 & 0.8 & $3.3(h / 100)$ & 1.5 & 1.8 & 1.0 & 0.9 & $3.3(h / 100)$ \\
\hline
\end{tabular}

Note: $h$ denotes the height of the relevant story.

midstory isolated structure without a protective system were less than those with the protective system, since the failure of the isolated structure without the protective system has been ignored. In fact, the maximum deformation of the isolation layer without a protective system reached $50.9 \mathrm{~cm}$ and $49.5 \mathrm{~cm}$. They both greatly exceeded the permissible deformation of lead-rubber bearings, which resulted in the failure of the isolation layer and could further lead to the overturning collapse of the superstructure. Consequently, the isolation effects without the protective system are imaginary but not actual. On the contrary, the maximum deformations in the isolation layer with a protective system were reduced to $35.6 \mathrm{~cm}$ and $35 \mathrm{~cm}$, less than the permissible deformation of lead-rubber bearings, which prevented the destruction of the isolation layer. This is because the linear spiral spring began its function to limit the deformation of the isolation layer. This indicates that when subjected to strong nonpulse ground motion, such as in CHY029N and HDLT352, plastic interstory drifts of the midstory isolated structure with the protective system are somewhat greater than those without the protective system since the linear spiral spring took its function and the maximum deformations of the isolation layer decreased. It is important to note that all of these plastic interstory drifts with protective systems are lower than the limitation value specified in the Chinese seismic design code [22] and they still meet the interstory drift requirements. Meanwhile, all of the maximum deformations of the isolation layer are also lower than the reserve space $d_{u}$, indicating that the superfloor above the isolation system will not collide with the high-damping rubber bumper.

To analyze the effects of the protective system's parameters, such as reserve space $d_{0}$ and limiting stiffness $k_{s}$, on seismic performance of the isolated structure, numeral simulations were carried out for the isolated structure with a protective system under the various earthquake records in Table 2, in which the value of peak ground acceleration shown has been scaled to $400 \mathrm{~cm} / \mathrm{s}^{2}$. Without any loss of generality, the results of the simulations under HE04230 and CHY029N earthquake records have been selected in Figures 12 and 13.

Figure 12 describes the effects of limiting stiffness in response to the midstory isolated structure under different earthquake waves. As shown in Figure 12(a), when subjected to a pulse-like HE04230 earthquake record, the maximum deformation of the isolation layer decreased with the increase of limiting stiffness $k_{s}$ under the condition of the same reserve space $d_{0}$. When the limiting stiffness $k_{s} \geq 10000 \mathrm{kN} / \mathrm{m}$, the maximum deformation of isolation layer did not exceed the allowable deformation of the lead-rubber bearings. It was also observed that limiting stiffness $k_{s}$ had little influence on the plastic interstory drift ratio of the substructure. However, the plastic interstory drift ratio of the superstructure increased significantly with the increase of limiting stiffness $k_{s}$; we noted that when limiting stiffness $k_{s}$ was greater than a certain value, the plastic interstory drift ratio of the superstructure was greater than that of the aseismic structure, which had an adverse impact on the superstructure. As can be seen in Figure 12(b), when subjected to a nonpulse CHY029N earthquake record, it was observed that the maximum deformation of the isolation layer decreased with the increase of limiting stiffness $k_{s}$ and the plastic interstory drift ratio of the superstructure increased slightly with the increase of limiting stiffness $k_{s}$. Thus, the relationship between limiting stiffness $k_{s}$, the maximum deformation, and the plastic interstory drifts ratio should be comprehensively considered to select a reasonable limiting stiffness.

Figure 13 depicts the effects of reserve spaces in response to the midstory isolated structure under different earthquake waves. It can be observed from Figure 13(a) that the maximum deformation of the isolation layer increased with the increase in reserve space $d_{0}$ under the condition of the same limiting stiffness $k_{s}$. When the reserve space $d_{0}$ was greater than a certain value, the maximum deformation of the isolation layer exceeded the allowable deformation of the lead-rubber bearings. The results also show that reserve space 

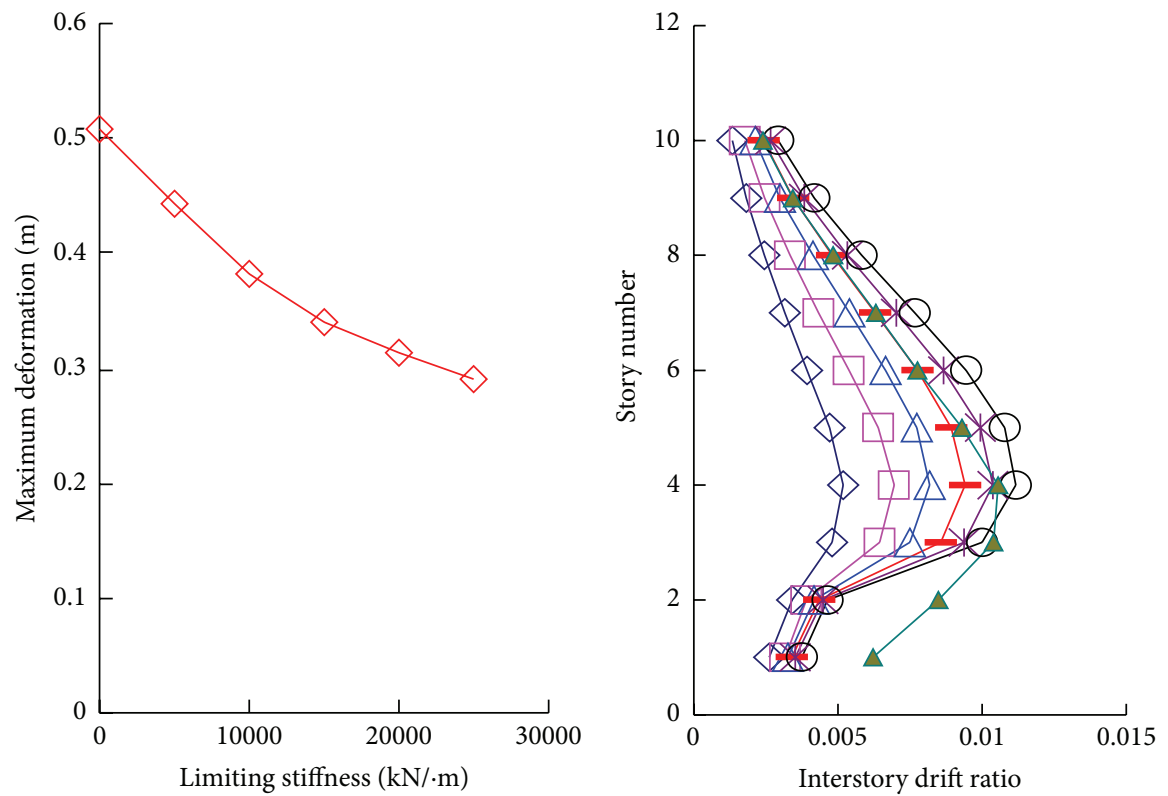

$$
\begin{array}{ll}
\smile k_{s}=0 & \rightarrow-k_{s}=20000 \\
\square k_{s}=5000 & \multimap-k_{s}=25000 \\
\triangle k_{s}=10000 & \smile \text { Aseismic } \\
-k_{s}=15000 &
\end{array}
$$

(a)
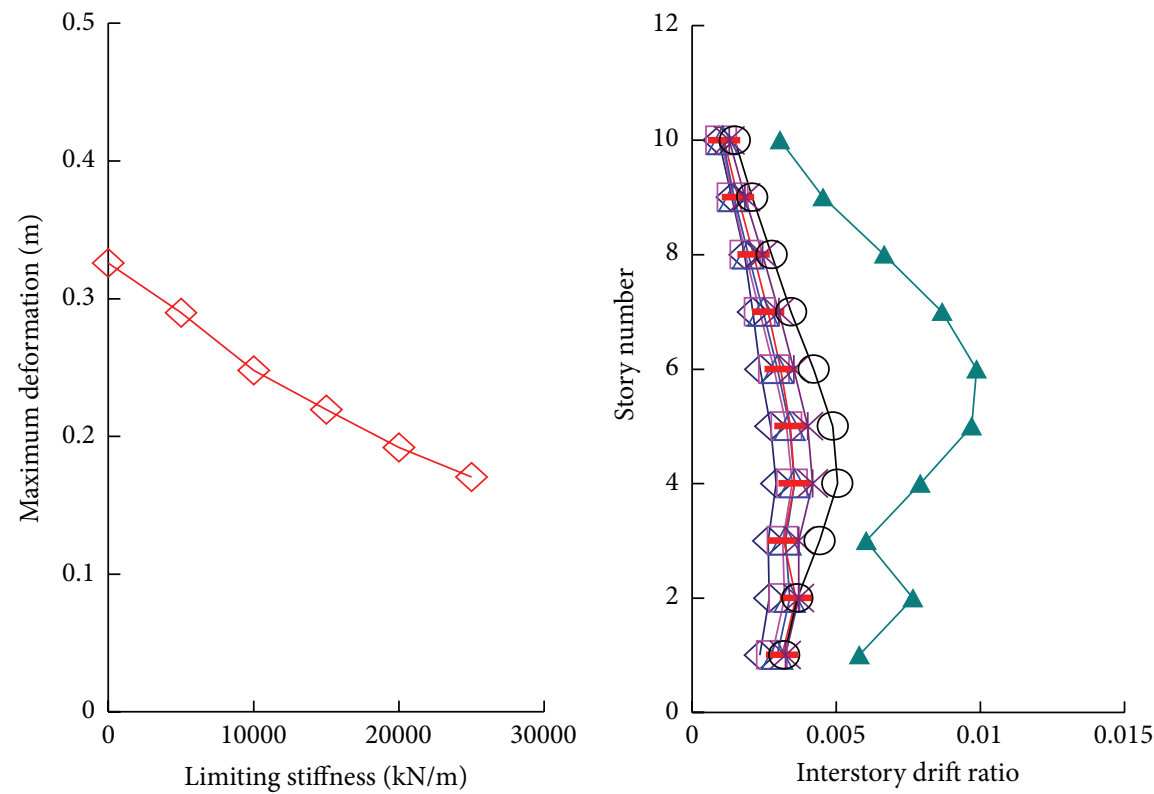

$$
\begin{aligned}
& \diamond k_{s}=0 \\
& \square k_{s}=5000 \\
& \text { * } k_{s}=20000 \\
& \triangle k_{s}=10000 \\
& -k_{s}=25000 \\
& -k_{s}=15000 \\
& \neg \text { Aseismic }
\end{aligned}
$$

(b)

FIGURE 12: Effect of limiting stiffness on response of midstory isolated structure under different earthquake waves. (a) HE04230; (b) CHY029N. 

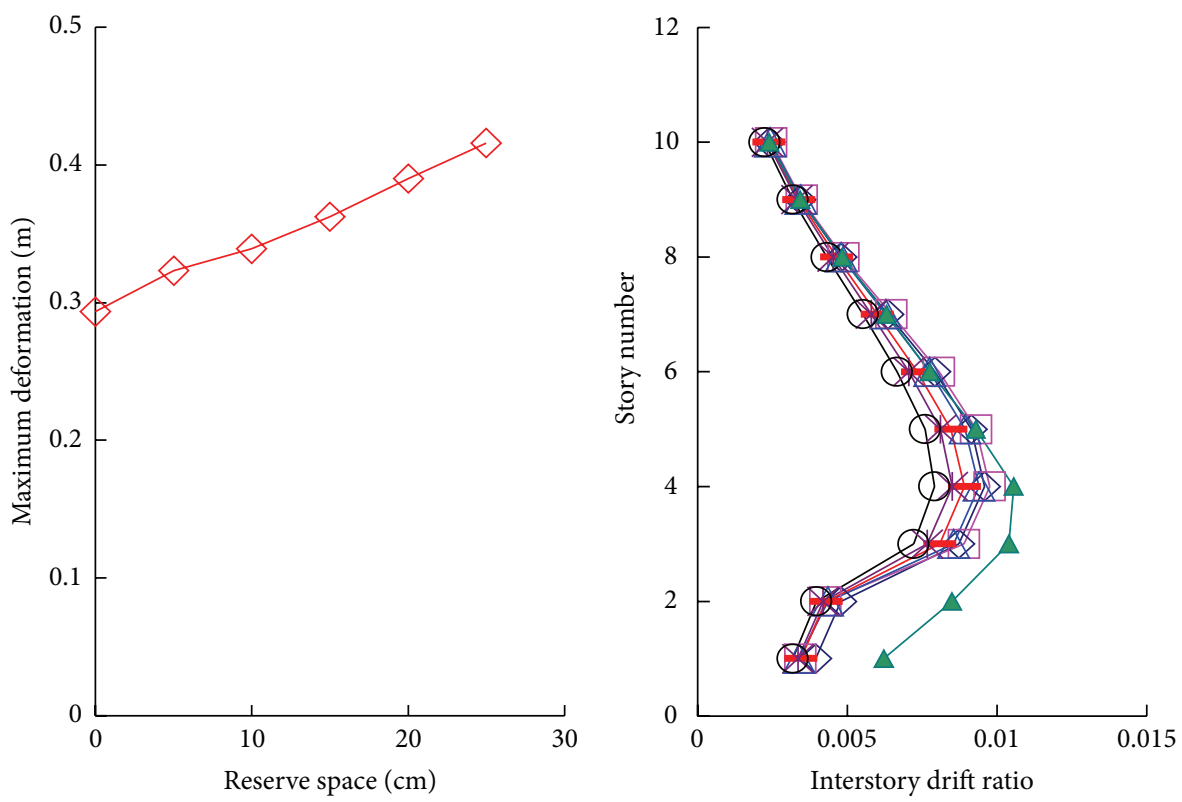

$$
\begin{aligned}
& \diamond d_{0}=0 \quad \rightarrow-d_{0}=20 \\
& \square d_{0}=5 \\
& \triangle d_{0}=10 \\
& -d_{0}=15 \\
& \multimap d_{0}=25 \\
& \neg \text { Aseismic }
\end{aligned}
$$

(a)
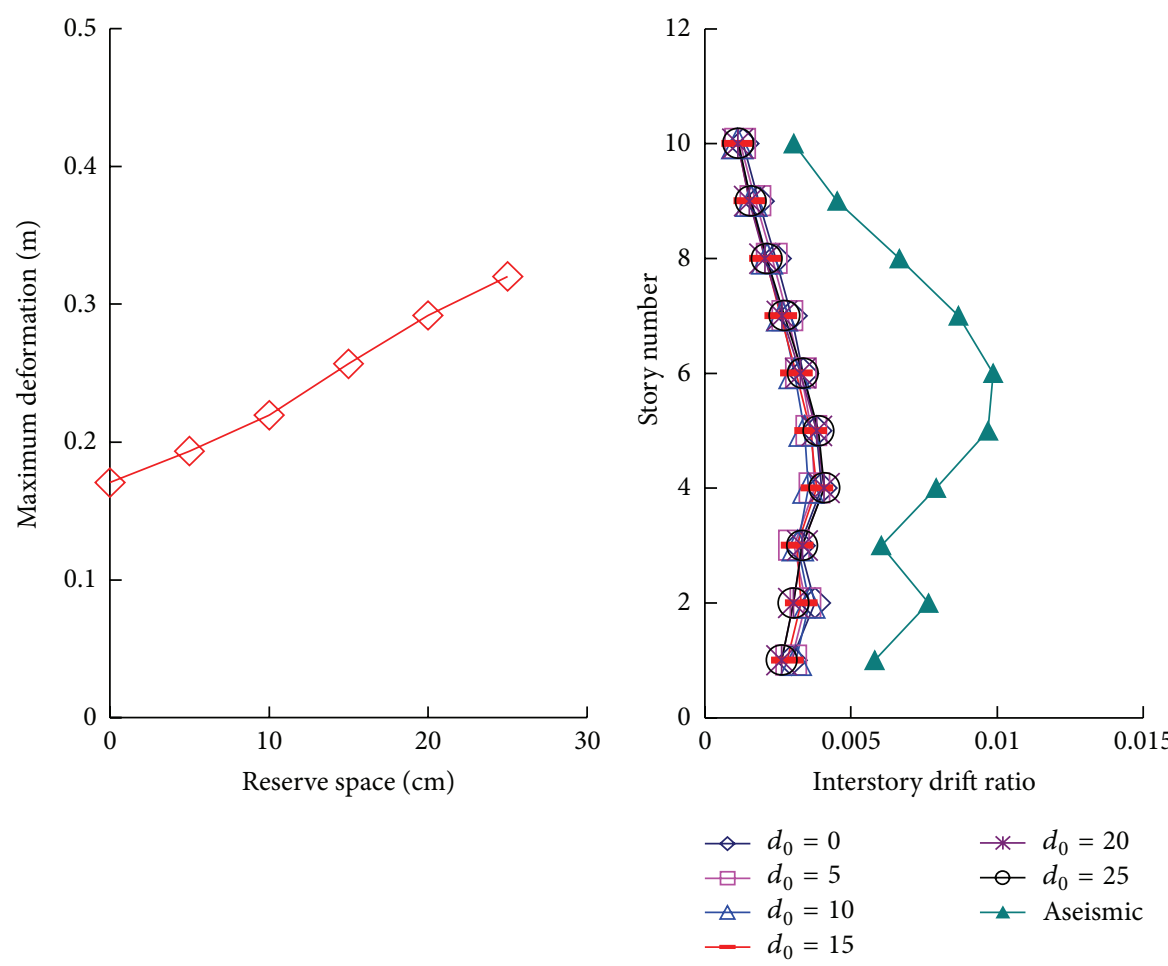

(b)

FIGURE 13: Effect of reserve spaces on response of midstory isolated structure under different earthquake waves. (a) HE04230; (b) CHY029N. 


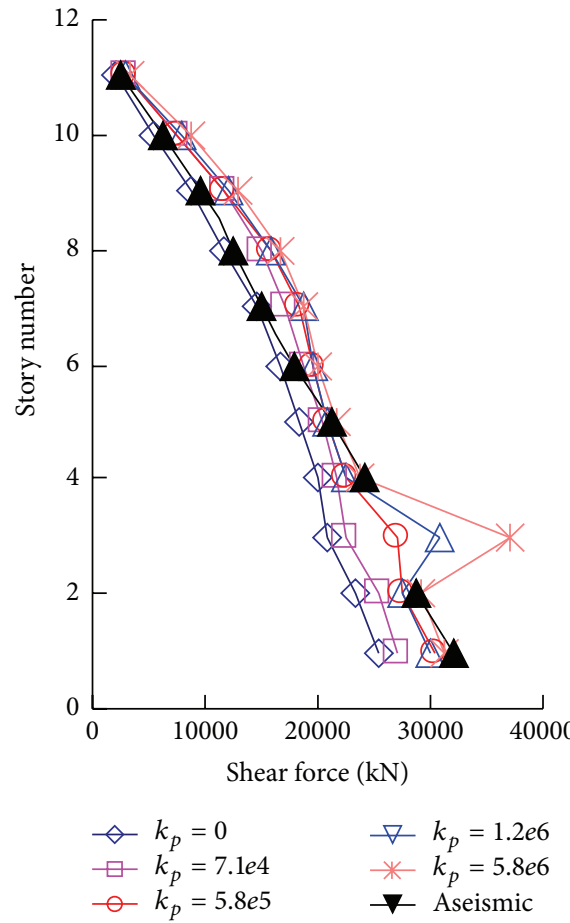

(a)

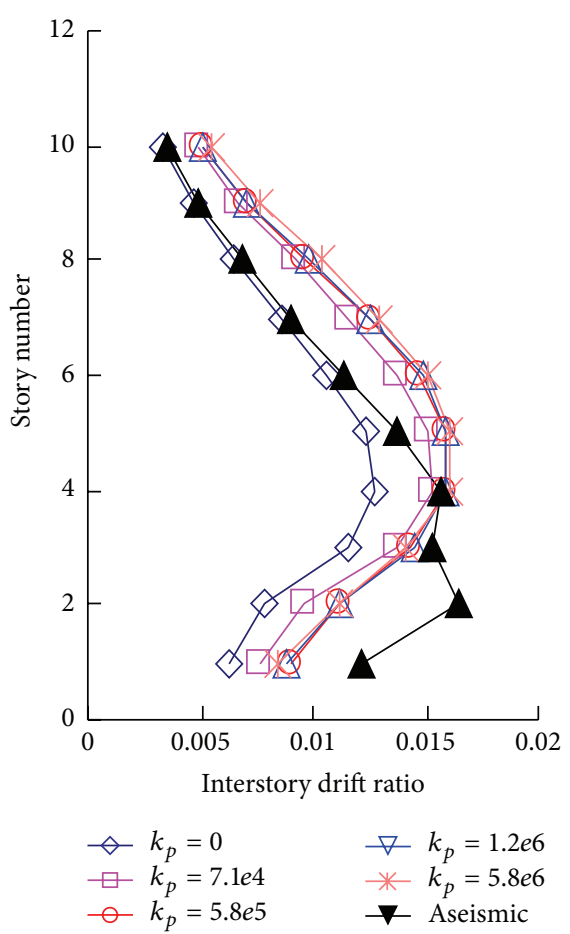

(b)

FIGURE 14: Impacts of pounding stiffness on responses of midstory isolated structure. (a) Peak shear force along height of building; (b) plastic interstory drift ratio.

$d_{0}$ had little influence on the plastic interstory drift ratio of the substructure. However, the plastic interstory drift ratio of the superstructure decreased with the increase of reserve space $d_{0}$, especially from the 3 rd floor to the 6 th floor. Figure 13(b) shows that the maximum deformation of the isolation layer increased with the increase of reserve space $d_{0}$ and the reserve space $d_{0}$ had little impact on the plastic interstory drift ratio for the isolated structure. Hence, the relationship between reserve space $d_{0}$, the maximum deformation, and the plastic interstory drift ratio should be comprehensively taken into account to select a reasonable reserve space $d_{0}$.

When the midstory isolated structure is excited by strong ground movement which is beyond preassumption, excessive deformation of the isolation layer may still occur if only the liner spiral spring plays a role in limiting the deformation of the isolation layer. Thus, the high-damping rubber bumper was further used to limit the deformation of isolation layer through soft pounding. Numeral simulations were carried out for the isolated structure with a protective system under various earthquake records in Table 2, in which the value of the peak ground acceleration was scaled to $510 \mathrm{~cm} / \mathrm{s}^{2}$. The results show that when subjected to nonpulse earthquake records, the maximum deformation of the isolation layer does not exceed the allowable deformation of lead-rubber bearings if only the liner spiral spring limited deformation of the isolation layer; on the contrary, this maximum deformation exceeded the allowable deformation when subjected to pulselike earthquake records. The results under the pulse-like HE04230 earthquake record have been selected in Figures 14

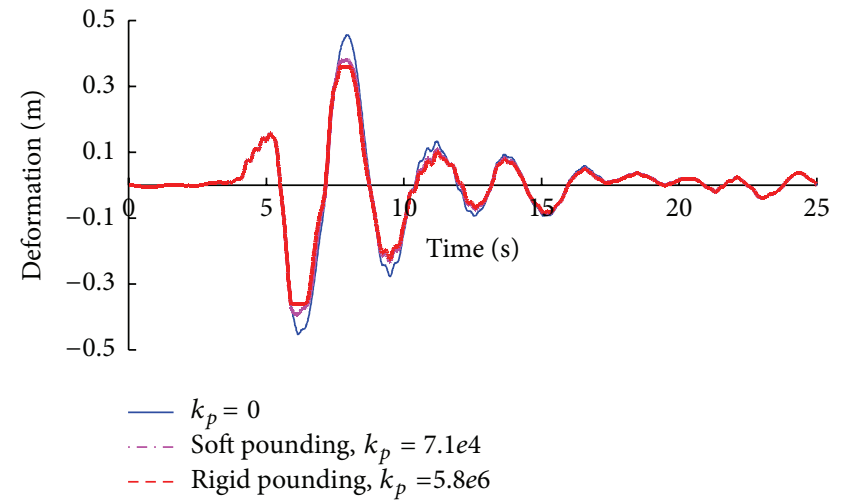

FIGURE 15: Comparison of the deformation history-time cure of the isolation layer with different pounding stiffness.

and 15 to illustrate the effects of pounding stiffness $k_{p}$ on the responses of the midstory isolated structure.

Figure 14 shows impacts of pounding stiffness $k_{p}$ on peak shear force and the plastic interstory drift ratio associated with the midstory isolated structure, where the parameter values of the above-mentioned protective system are still $d_{0}=$ $5 \mathrm{~cm}, k_{s}=10000 \mathrm{kN} / \mathrm{m}$, and $d_{u}=36 \mathrm{~cm}$. According to the previous literature [23], rigid pounding stiffness $k_{p}$ is equal to $5.8 \times 10^{6} \mathrm{kN} / \mathrm{m}$. The other pounding stiffness $k_{p}$ varies from $0 \mathrm{kN} / \mathrm{m}$ to $5.8 \times 10^{6} \mathrm{kN} / \mathrm{m}$. 
From Figure 14(a), note that pounding stiffness $k_{p}$ has a notable impact on the peak shear force of the isolation layer, and the peak shear force of the isolation layer increased as pounding stiffness $k_{p}$ increased. When rigid pounding occurred, the peak shear force of the isolation layer reached its maximum value and was 1.65 times as much as that of pounding stiffness $k_{p}=71000 \mathrm{kN} / \mathrm{m}$ and also exerted a negative effect on the piers and connectors of the leadrubber bearings. It was also observed that the peak shear force of the superstructure was enlarged by pounding when compared with the peak shear force of aseismic structure, while the peak shear force of substructure decreased slightly. As shown in Figure 14(b), plastic interstory drift ratio of the superstructure amplified remarkably in comparison with that of the aseismic structure while this drift ratio of the substructure decreased. This indicates that the failure mode for the midstory isolated structure likely changed from the instantaneous destruction of the isolation layer to the plastic damage of the superstructure, despite the fact that the maximum deformation of the isolation layer is lower than the allowable deformation of lead-rubber bearings.

Figure 15 presents a comparison of the deformation history-time cure of the isolation layer with the above-mentioned pounding stiffness. It was observed that the maximum deformation of the isolation layer could reach $45.6 \mathrm{~cm}$ if only the liner spiral spring played a role in the limiting deformation of the isolation layer. This deformation exceeds the allowable deformation of lead-rubber bearings and would further result in the destruction of the lead-rubber bearings. If rigid pounding occurred, the maximum deformation of isolation layer would be reduced to $36 \mathrm{~cm}$. However, rigid pounding led to the increase of shear force of isolation layer, as shown in Figure 14(a). This produced an adverse impact on the piers and connectors of the lead-rubber bearings. If the high-damping rubber bumper was used to limit deformation of the isolation layer by soft pounding, the maximum deformation of isolation layer was reduced to $39.1 \mathrm{~cm}$, which is somewhat greater than the allowable deformation of lead-rubber bearings for the ignorance of energy dissipation of the bumper during collision.

From the above discussion, it can be concluded that if the parameters of reserve space $d_{0}$, limiting stiffness $k_{s}$, pounding reserve space $d_{u}$, and pounding stiffness $k_{p}$ are properly selected, the protective system does not influence the isolation effect when subject to small ground movements. Moreover, the protective system can limit the maximum deformation of the isolation layer and can effectively reduce nonlinear responses of the isolated structure when subject to strong ground motion, preventing the superstructure's collapse. In extreme cases, when strong ground movements are beyond preassumption, the protective system also restricts the maximum deformation of the isolation layer, preventing instantaneous collapse of the superstructure. It is worth noting that the plastic interstory drift ratio of the superstructure is larger when compared with that of the aseismic structure, which probably results in the failure mode changing from the instantaneous collapse of the superstructure to plastic damage of the superstructure.

\section{Conclusions}

In this study, a protective system for limiting the deformation of the isolation layer has been developed and a new method that synthesizes artificial near-field pulse-like ground motion has also been proposed. In addition, comparative analyses for the midstory isolated structure subject to near-field pulse-like ground movements were conducted. The outcomes of this study are summarized as follows.

(1) Nonlinear responses of the midstory isolated structure and the maximum deformation of the isolation layer under near-field pulse-like ground motion were much greater than those under nonpulse ground motion and were affected by the characteristic parameters of near-field ground motion, such as pulse type, pulse period, and pulse contribution factor. The maximum deformation of the isolation layer significantly exceeded the allowable deformation of leadrubber bearings, which destroyed the lead-rubber bearings and further resulted in the collapse of the superstructure. Thus, a midstory isolation design that employs conventional lead-rubber bearings is inappropriate in a near-field region.

(2) The proposed protective system is effective in restricting the excessive deformation of the isolation layer and reducing nonlinear responses of the isolated structure when subject to strong pulse-like ground motion, especially the substructure, preventing the collapse of the superstructure. Even if strong pulse-like ground motion is beyond preassumption, the protective system can also restrict the maximum deformation of the isolation layer, preventing instantaneous collapse of the superstructure. However, the plastic interstory drift ratio of the superstructure is amplified when compared to that of the aseismic structure, which may result in the fact that the failure mode changes from the instantaneous collapse of the superstructure to plastic damage of the superstructure.

\section{Conflict of Interests}

The authors declare that there is no conflict of interests regarding the publication of this paper.

\section{Acknowledgments}

The research presented herein was supported by the National Natural Science Foundation of China (Grant nos. 51378124 and 51108083), Fujian Province Natural Science Foundation of China (Grant no. 2013J01169), and Fujian Province Educational Special Foundation of China (Grant no. JK2012035). The writers wish to express their sincere gratitude to the sponsors.

\section{References}

[1] K. Ogura, M. Takayama, O. Tsujita, Y. Kimura, and A. Wada, "Seismic response of mid-story isolated buildings," Journal of Structural and Construction Engineering, no. 516, pp. 99-104, 1999.

[2] T. Koh and M. Kobayashi, "Vibratory characteristics and earthquake response of mid-story isolated buildings," Memoirs of the 
Institute of Sciences and Technology, Meiji University, vol. 39, no. 12, pp. 97-114, 2000.

[3] K. Murakami, H. Kitamura, and Y. Matsushima, "The prediction for seismic responses of the two-mass model with the midstory isolation system," Journal of Structural and Construction Engineering, Architectural Institute of Japan, no. 549, pp. 51-58, 2001.

[4] T. Koh and M. Kobayashi, "Analytical study of modal coupling effect on mid-story isolation system by Eigen value analysis and random vibration analysis," in Summaries of Technical Papers of Annual Meeting, Architectural Institute of Japan, B-2, Structures II, Structural Dynamics Nuclear Power Plants, pp. 333-334, 2004.

[5] S.-J. Wang, K.-C. Chang, J.-S. Hwang, and B.-H. Lee, "Simplified analysis of mid-story seismically isolated buildings," Earthquake Engineering and Structural Dynamics, vol. 40, no. 2, pp. 119-133, 2011.

[6] S. J. Wang, J. S. Hwang, K. C. Chang, M. H. Lin, and B. H. Lee, "Analytical and experimental studies on midstory isolated buildings with modal coupling effect," Earthquake Engineering and Structural Dynamics, vol. 42, no. 2, pp. 201-219, 2013.

[7] C.-H. Loh, J.-H. Weng, C.-H. Chen, and K.-C. Lu, "System identification of mid-story isolation building using both ambient and earthquake response data," Structural Control and Health Monitoring, vol. 20, no. 2, pp. 139-155, 2013.

[8] F. Mazza and A. Vulcano, "Nonlinear response of RC framed buildings with isolation and supplemental damping at the base subjected to near-fault earthquakes," Journal of Earthquake Engineering, vol. 13, no. 5, pp. 690-715, 2009.

[9] F. Mazza, A. Vulcano, and M. Mazza, "Nonlinear dynamic response of RC buildings with different base Isolation systems subjected to horizontal and vertical components of near-fault ground motions," Open Construction and Building Technology Journal, vol. 6, pp. 373-383, 2012.

[10] F. Mazza and A. Vulcano, "Effects of near-fault ground motions on the nonlinear dynamic response of base-isolated r.c. framed buildings," Earthquake Engineering and Structural Dynamics, vol. 41, no. 2, pp. 211-232, 2012.

[11] P. Tan, W.-X. Yin, and Y. Zhang, "Seismic control of interstory isolated eccentric structure subjected to near-field ground motion," Journal of Vibration and Shock, vol. 30, no. 11, pp. 281286, 2011 (Chinese).

[12] H. Li, C. Bao, and Y. F. Du, "Dynamic response analysis of irregular story isolation structures under near-field earthquake conditions," China Earthquake Engineering Journal, vol. 35, no. 1, pp. 51-55, 2013 (Chinese).

[13] C.-F. Ma, P. Tan, Y.-H. Zhang, and F.-L. Zhou, "Seismic analysis of first-floor column top isolation structures subjected to near-field ground motions considering P- $\triangle$ effects," Journal of Vibration Engineering, vol. 25, no. 4, pp. 439-445, 2012.

[14] Y. F. Du and X. H. Wang, "Collapse simulation of the serial isolation structure subjected to multi-dimensional earthquake," Earthquake Resistant Engineering and Retrofitting, vol. 34, no. 6, pp. 50-54, 2012 (Chinese).

[15] S. A. Anagnostopoulos, "Equivalent viscous damping for modeling inelastic impacts in earthquake pounding problems," Earthquake Engineering \& Structural Dynamics, vol. 33, no. 8, pp. 897-902, 2004.

[16] R. Jankowski, K. Wilde, and Y. Fujino, "Reduction of pounding effects in elevated bridges during earthquakes," Earthquake Engineering \& Structural Dynamics, vol. 29, no. 2, pp. 195-212.
[17] J. Fan, T. Liu, and J. J. Wei, "Response and protection of the impact of base-friction-isolated structures and displacementconstraint devices under near-fault earthquakes," China Civil Engineering Journal, vol. 40, no. 5, pp. 10-16, 2007 (Chinese).

[18] Y.-K. Wen, "Method for random vibration of hysteretic systems," Journal of the Engineering Mechanics Division, vol. 102, no. 2, pp. 249-263, 1976.

[19] C.-H. Loh, S. Wan, and W.-I. Liao, "Effects of hysteretic model on seismic demands: consideration of near-fault ground motions," The Structural Design of Tall Buildings, vol. 11, no. 3, pp. 155-169, 2002.

[20] M. Dicleli and S. Buddaram, "Equivalent linear analysis of seismic-isolated bridges subjected to near-fault ground motions with forward rupture directivity effect," Engineering Structures, vol. 29, no. 1, pp. 21-32, 2007.

[21] S. W. Park, H. Ghasemi, J. Shen, P. G. Somerville, W. P. Yen, and M. Yashinsky, "Simulation of the seismic performance of the Bolu Viaduct subjected to near-fault ground motions," Earthquake Engineering and Structural Dynamics, vol. 33, no. 13, pp. 1249-1270, 2004.

[22] National Standard of the People's Republic of China, Code for Seismic Design of Building (GB 50011-2010), Ministry of Construction of Peoples Republic of China, Beijing, China, 2010.

[23] S. Muthukumar and R. DesRoches, "A Hertz contact model with non-linear damping for pounding simulation," Earthquake Engineering \& Structural Dynamics, vol. 35, no. 7, pp. 811-828, 2006. 

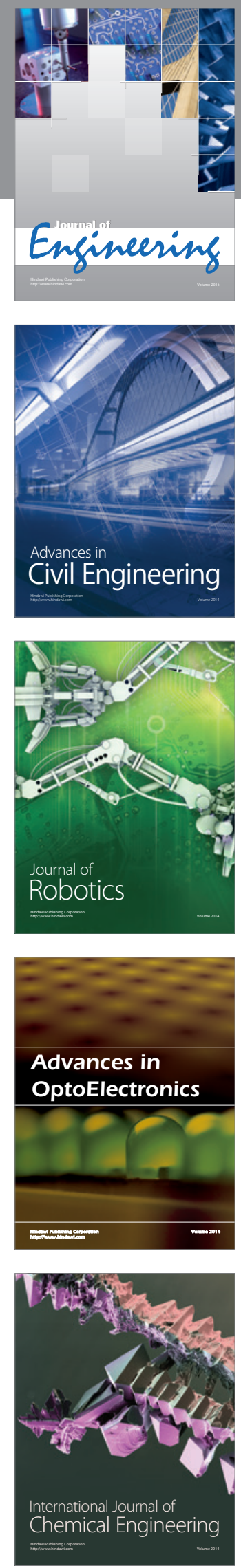

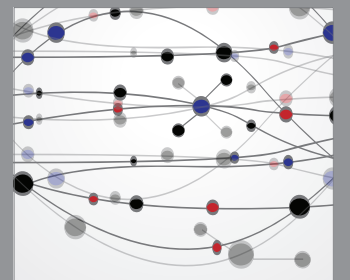

The Scientific World Journal
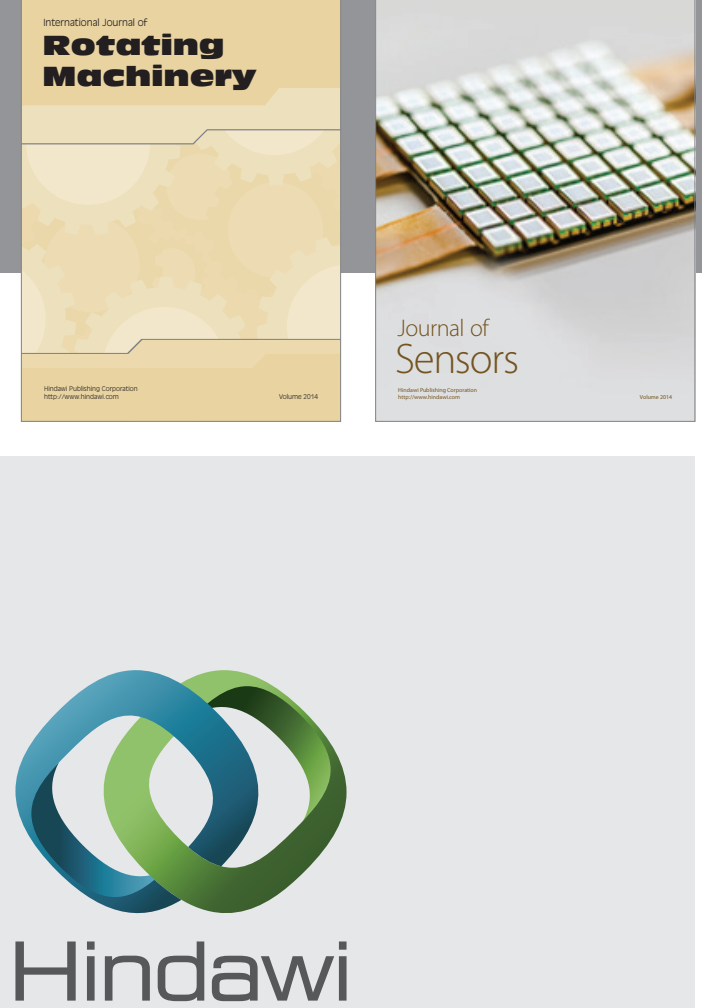

Submit your manuscripts at http://www.hindawi.com
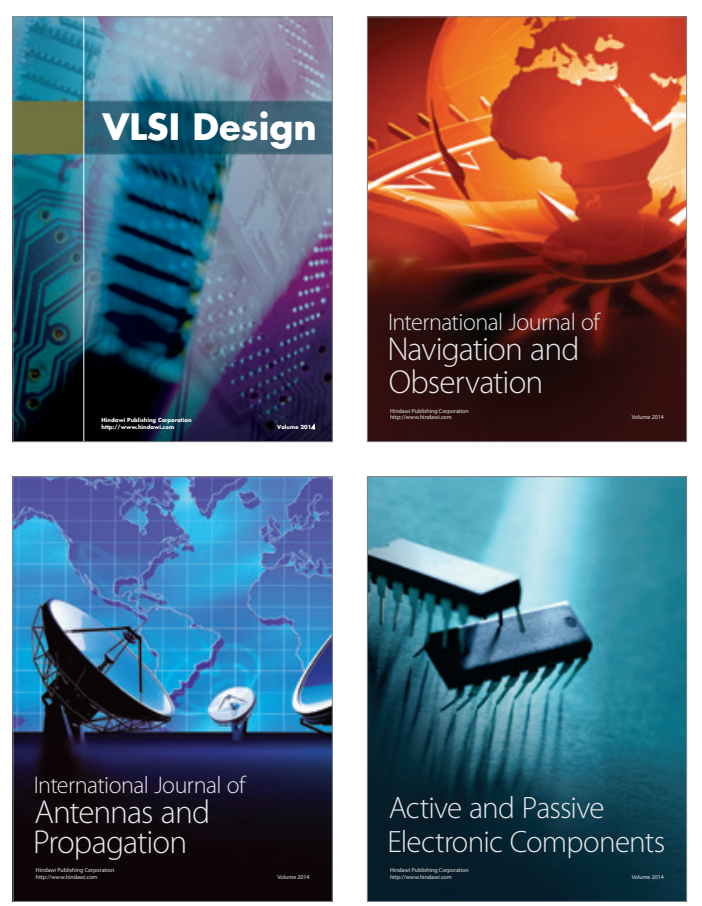
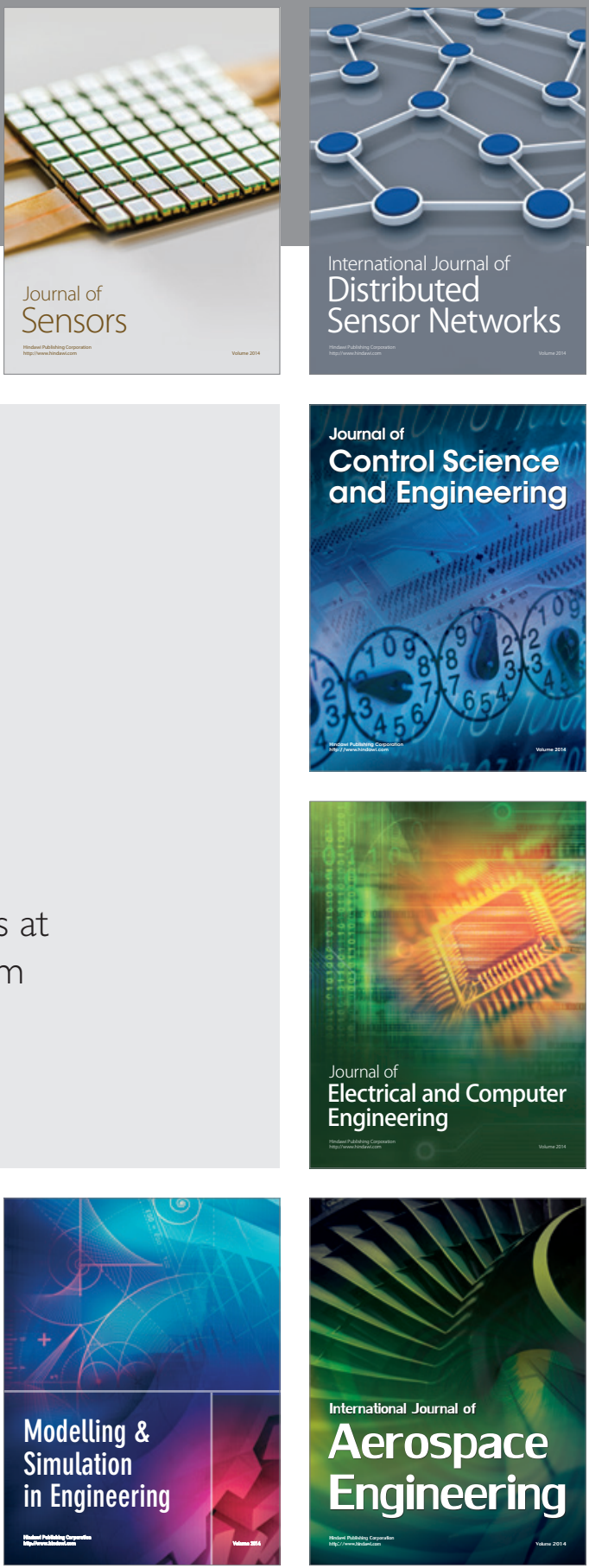

Journal of

Control Science

and Engineering
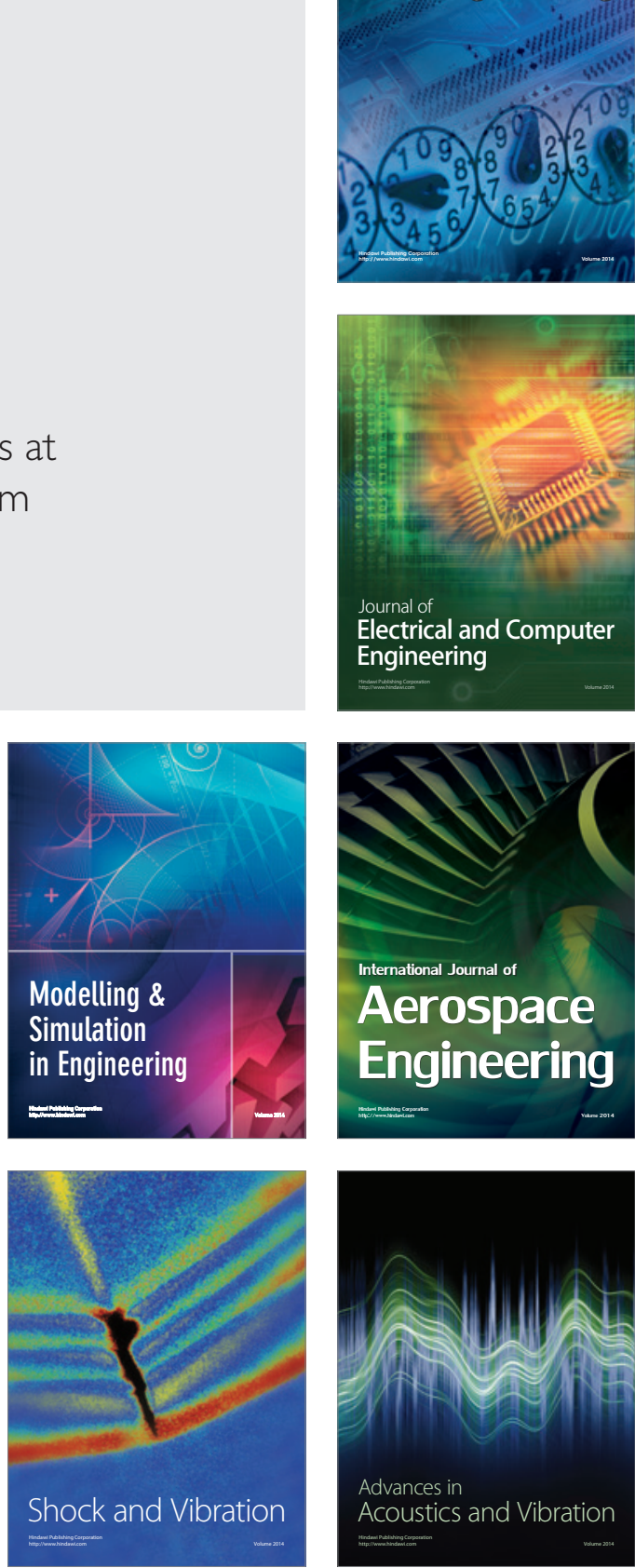